NIST PUBLICATIONS
NBSIR 78-1548 \begin{tabular}{l} 
An Evaluation of ASHRAE \\
Standard $94-77$ for Testing \\
Water Tanks for Thermal \\
Storage \\
\hline
\end{tabular}

B. J. Hunt

T. E. Richtmyer

J. E. Hill

Building Thermal and Service Systems Division Center for Building Technology National Engineering Laboratory National Bureau of Standards Washington, D.C. 20234

October 1978

Sponsored by

The Department of Energy

Research \& Development Branch for Solar Heating and Cooling

QC Office of the Assistant Secretary for Conservation and Solar Applications Washington, D.C. 20545 


\title{
AN EVALUATION OF ASHRAE STANDARD 94-77 FOR TESTING WATER TANKS FOR THERMAL STORAGE
}

\author{
B. J. Hunt \\ T. E. Richtmyer \\ J. E. Hill
}

Building Thermal and Service Systems Division Center for Building Technology National Engineering Laboratory National Bureau of Standards Washington, D.C. 20234

October 1978

Sponsored by

The Department of Energy

Research \& Development Branch for Solar Heating and Cooling Office of the Assistant Secretary for Conservation and

Solar Applications

Washington, D.C. 20545

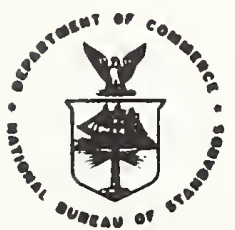

U.S. DEPARTMENT OF COMMERCE, Juanita M. Kreps, Secretary Dr. Sidney Harman, Under Secretary

Jordan J. Baruch, Assistant Secrotary for Scionce and Technology NATIONAL BUREAU OF STANDARDS. Ernest Ambler, Director 

CONTENTS

$\underline{\text { Page }}$

Abstract.................................. iv

1. Introduction...............................

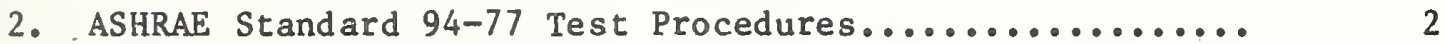

3. NBS Test Facility............................ 8

4. Experimental Procedure........................ 15

5. Test Results and Analysis........................ 29

6. Discussion of Results.......................... 38

7. Conclusion and Recommendations................... 46

8. References............................... 47

9. Appendix A. Time-Temperature Relationships for the Transfer Fluid during the Transient Storage Tests...

10. Appendix B. Dimensionless Time-Temperature Relationships for the Transfer Fluid during The Transient

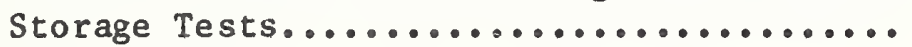


TABLES

Table 1. Transient test parameters used for the charge and discharge tests.

Table 2. Results of the transient tests performed on the $1.9 \mathrm{~m}^{3}$ (500 gal) water tank.

Table 3. Rating coefficients for the $1.9 \mathrm{~m}^{3}$ (500 gal) water tank.

Table 4. Times for the achievement of the step-change in entering transfer fluid temperature during the transient tests.

Table 5. Mass flow rates per tank cross sectional area for the $1.9 \mathrm{~m}^{3}$ (500 ga 1) test tank and the test models of [13]. 


\section{INTRODUCTION}

Beginning in early 1974, the staff of the National Bureau of Standards (NBS) began the development of thermal test procedures for the two primary components of solar heating and cooling systems, solar collectors and thermal storage devices. Recommended procedures for testing these two components were published in December 1974 and May 1975, respectively, $[1,2]$ in a format consistent with standard test procedures of the American Society of Heating, Refrigerating and Air Conditioning Engineers (ASHRAE). The procedures were later published with supplementary information explaining the rationale behind each procedure [3, 4, 5].

In July of 1975, ASHRAE formed Standards Project Committee 94-P to develop a standard for the testing of thermal storage devices. The NBSrecommend procedure [2] was submitted to the Committee as a working draft for their consideration. In June 1976, a draft of the Standard was published and submitted to the Society for review. It should be noted that the preparation of this proposed standard by the Project Committee was performed on an unusually accelerated schedule relative to the pace at which ASHRAE standards are normally written. This was partially a result of the previously published NBS-recommended procedure [2]. The ASHRAE draft was modified according to the review comments received and then forwarded to the ASHRAE Standards Committee for approval. In February, 1977, the ASHRAE Board of Directors approved and authorized publication of ASHRAE Standard 94-77, "Methods of Testing Thermal Storage Devices Based on Thermal Performance" [6].

The purpose of this report is to describe the results of an experimental study conducted at NBS during 1977 in which a $1.9 \mathrm{~m}^{3}$ (500 gal) water thermal storage tank was tested in accordance with Standard 94-77. The study demonstrates the applicability of the Standard to this type of sensible-heat storage device for liquid systems. Similar experiments are presently being conducted at NBS on residentialsize pebble-bed and phase-change storage devices for air systems. The results of these experiments are expected to be completed and published before the end of 1978 .

It should be noted that a similar and parallel standards development process occurred utilizing the NBS-recommended test procedure for solar collectors [1]. ASHRAE Standard 93-77, "Methods of Testing to Determine the Thermal Performance of Solar Collectors" was adopted and published in February, 1977 [7]. NBS has conducted a series of experiments demonstrating the use of this Standard for testing typical commercially available water-heating and air-heating collectors [8]. 


\section{ASHRAE STANDARD 94-77 TEST PROCEDURES}

The method outlined in ASHRAE Standard 94-77 for testing thermal storage devices consists of the following:

1. one test to determine the heat-loss factor, $\mathrm{L}$, of the thermal storage device (Heat Loss Test),

2. two tests to determine the charge capacity, $c_{c}$, of the device as the result of a step increase in the entering transfer fluid temperature (Charge Test), and

3. two tests to determine the discharge capacity, $C_{D}$, of the device as the result of a step decrease in the entering transfer fluid temperature (Discharge Test).

\section{Heat Loss Test}

The heat loss test consists of passing the transfer fluid through the storage device with an inlet temperature of $25^{\circ} \mathrm{C}\left(45^{\circ} \mathrm{F}\right)$ above the ambient air temperature. After steady-state conditions are obtained, measurements are made of the average temperature difference between the inlet and outlet transfer fluid and are recorded over a one-hour period (see Figure 1). Steady-state conditions are achieved by circulating the transfer fluid through the storage device until the inlet and outlet transfer fluid temperatures vary by less than $\pm 0.5^{\circ} \mathrm{C}\left( \pm 0.9^{\circ} \mathrm{F}\right)$ during a one-hour period.

The heat loss factor is defined in the Standard by:

$$
L=\frac{w_{L} c_{t f}}{(3600 s)\left(25^{\circ} \mathrm{C}\right)} \int_{\tau=0}^{3600}\left(t_{\text {in }}-t_{\text {out }}\right) d \tau
$$

where,

$$
\begin{aligned}
\mathrm{L}= & \text { heat loss factor } \mathrm{J} /\left(\mathrm{s}^{\circ}{ }^{\circ} \mathrm{C}\right)\left(\mathrm{Btu} /\left(\mathrm{h}^{\circ}{ }^{\circ} \mathrm{F}\right)\right) \\
\mathrm{w}_{\mathrm{L}=} & \text { mass flow rate of the transfer fluid } \\
& \text { for the heat loss test, } \mathrm{kg} / \mathrm{s}(1 \mathrm{~b} / \mathrm{h}) \\
\mathrm{t}_{\text {in }}= & \text { temperature of the transfer fluid entering } \\
& \text { the storage device, }{ }^{\circ} \mathrm{C}\left({ }^{\circ} \mathrm{F}\right) \\
\mathrm{t}_{\text {out }}= & \text { temperature of the } \operatorname{transfer} \text { fluid leaving } \\
& \text { the storage device, }{ }^{\circ} \mathrm{C}\left({ }^{\circ} \mathrm{F}\right) \\
\mathrm{c}_{\mathrm{tf}}= & \text { specific heat of the transfer fluid, } \\
& \mathrm{J} /\left(\mathrm{kg} \cdot{ }^{\circ} \mathrm{C}\right)\left(\mathrm{Btu} /\left(1 \mathrm{~b} \cdot{ }^{\circ} \mathrm{F}\right)\right) .
\end{aligned}
$$




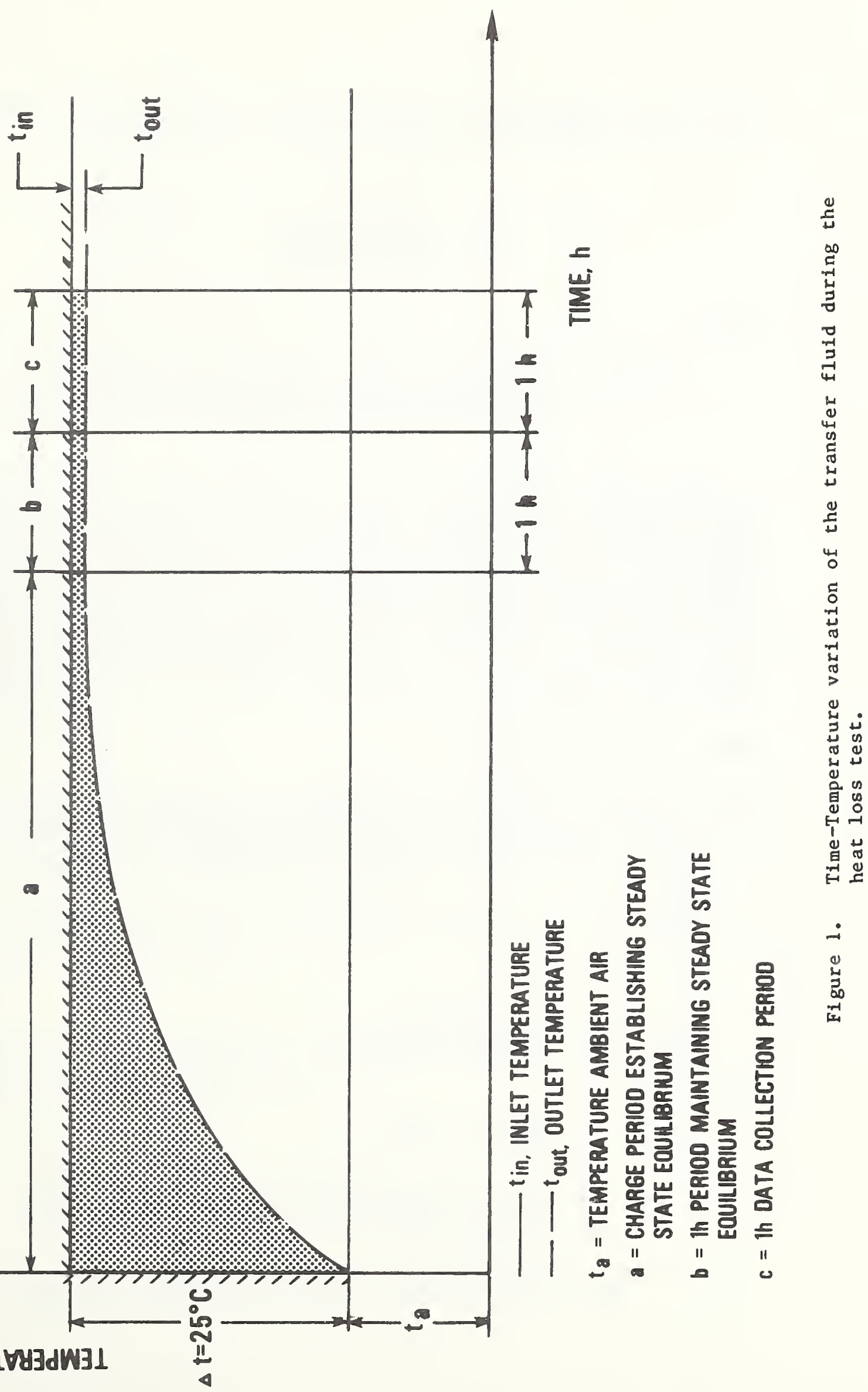


The mass flow rate of the transfer fluid to be used for the heat loss test is determined by:

$$
w_{L}=\frac{\mathrm{TSC}_{\mathrm{L}}}{\mathrm{c}_{\mathrm{tf}}(14400 \mathrm{~s})\left(25^{\circ} \mathrm{C}\right)}
$$

where,

$$
\begin{aligned}
\mathrm{TSC}_{\mathrm{L}}= & \text { theoretical storage capacity of the thermal } \\
& \text { storage device for the heat loss test, based } \\
& \text { on a } \Delta \mathrm{t}=25^{\circ} \mathrm{C}\left(45^{\circ} \mathrm{F}\right), \mathrm{J}(\mathrm{Btu}) .
\end{aligned}
$$

The theoretical storage capacity for the heat loss test is the amount of energy capable of being stored in the device if all the device components undergo an increase in temperature of $25^{\circ} \mathrm{C}\left(45^{\circ} \mathrm{F}\right)$ above an initial temperature equal to $t_{a}$, the ambient air temperature. It is further specified that it be calculated as the summation of the products of mass and specific heat of the various components comprising the thermal storage device (storage medium, tank, insulation, etc.) multiplied by the temperature step from the initial temperature, $t_{a}$, to a final temperature, $t_{a}$ $+25^{\circ} \mathrm{C}\left(\mathrm{t}_{\mathrm{a}}+45^{\circ} \mathrm{F}\right)$.

Charge and Discharge Tests:

These tests deal with the determination of the response characteristics of the thermal storage device to a temperature step increase or decrease in the inlet transfer fluid (charge and discharge tests, respectively). This quantifies the energy storage capabilities of the device.

In the Standard, the concept of test fill time is introduced and defined as :

$$
\tau_{f}=\frac{T S C}{w_{t f} c_{t f} \Delta t}
$$

where,

$$
\begin{aligned}
\tau_{f}= & \text { test fill time, } s \\
= & \text { duration of a single transient test in which } \\
& \text { energy is either added or extracted from the } \\
& \text { storage device, } \\
w_{t f}= & \text { mass flow rate of the transfer fluid, } \mathrm{kg} / \mathrm{s}(1 \mathrm{~b} / \mathrm{h})
\end{aligned}
$$




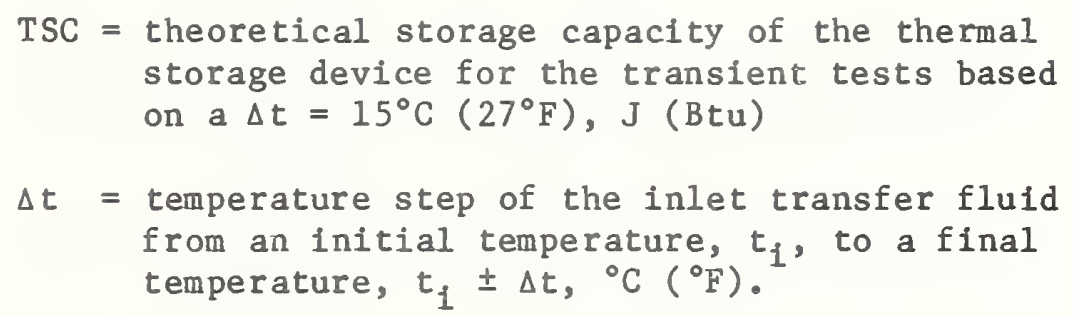

A water tank with no heat loss to the ambient and with perfect stratification of the storage medium would be completely charged or discharged in the time defined by equation (3). Since such an ideal storage device does not exist, the fill time defined above is found to be less than the time required to completely charge or discharge actual storage devices.

ASHRAE Standard 94-77 specifies that the charge and discharge tests be conducted for specific test fill times and step changes in the inlet transfer fluid temperature. The recommended temperature step change values for devices which use both air and liquid were based on consideration of the way in which they are currently used in typical solar heating and cooling systems [5]. The fill times were chosen based on typical ratios of solar collector size to storage size and flow rates required for optimum collector performance.

The recommended values specified in the Standard for devices using liquid as the transfer fluid are:

$$
\begin{aligned}
\tau_{\mathrm{c}}, \tau_{\mathrm{d}} & =7200 \mathrm{~s}(2 \mathrm{~h}) \\
\Delta t & =15^{\circ} \mathrm{C}\left(27^{\circ} \mathrm{F}\right)
\end{aligned}
$$

and

$$
\begin{aligned}
{ }^{\tau_{c}, \tau_{\mathrm{d}}} & =14400 \mathrm{~s}(4 \mathrm{~h}) \\
\Delta \mathrm{t} & =15^{\circ} \mathrm{C}\left(27^{\circ} \mathrm{F}\right) .
\end{aligned}
$$

With the test fill times designated, the mass flow rates are simply determined by use of equation (3). Therefore, the mass flow rates for the transient tests are defined as:

$$
\begin{aligned}
& w_{c}=\frac{T S C}{\tau_{c} c_{t f} \Delta t} \\
& w_{d}=\frac{T S C}{\tau_{d} c_{t f} \Delta t}
\end{aligned}
$$


where,

$$
\begin{aligned}
& w_{c}=\text { mass flow rate of the transfer fluid for the } \\
& \text { charge test, } \mathrm{kg} / \mathrm{s}(1 \mathrm{~b} / \mathrm{h}) \\
& w_{d}=\text { mass flow rate of the transfer fluid for the } \\
& \text { discharge test, } \mathrm{kg} / \mathrm{s}(1 \mathrm{~b} / \mathrm{h}) \\
& \tau_{c}=\text { test fill time for the charge test, } h \\
& \tau_{d}=\text { test fill time for the discharge test, } h \text {. }
\end{aligned}
$$

Figure $2 *$ represents the charge and discharge cycles of a thermal storage device undergoing the transient response tests in accordance with the Standard. The initial temperature of the storage medium is chosen based on the intended operating range of the device. After the device is brought to a uniform initial temperature (steady-state conditions), the flow is adjusted to the value, $w_{c}$, defined by equation (4). The temperature of the entering transfer fluid is then raised in a step-like manner from the initial temperature, $t_{i}$, to a final temperature, $t_{i}+\Delta t$, and measurements necessary for computing the charge capacity are made over the charge test fill time, $\tau_{c}$. The measurements required are the temperature difference between the transfer fluid inlet and outlet over the test fill time, the transfer fluid flow rate, and the ambient temperature. The storage medium is then allowed to reach steady-state conditions at the temperature $t_{i}+\Delta t$. This is represented by the asymptotic approach of the outlet temperature curve to being parallel to the inlet temperature curve shown in Figure 2. Once this steady-state condition is obtained, a discharge test is performed by decreasing the entering transfer fluid temperature in a step-like manner from $t_{i}+\Delta t$ to a value of $t_{1}$. Measurements necessary in computing the discharge capacity are then recorded over the discharge test fill time, ${ }^{\top} \mathrm{d}$. It should be noted that whenever the charge and discharge tests are performed in series as described above, the values of the test fill times ( $\tau_{c},{ }^{\top} d$ ) are equal as well as the temperature step increase and decrease ( $\Delta t$ ). Also, the flow rate established for the charge test $\left(w_{c}\right)$ is maintained the same for the discharge test $\left(w_{d}\right)$.

The charge and discharge capacities are defined in the Standard respectively as:

* Figure 2 is an ideal representation. Refer to the temperature vs. time plots in Appendix A for a representation of what occurs in an actual application. 


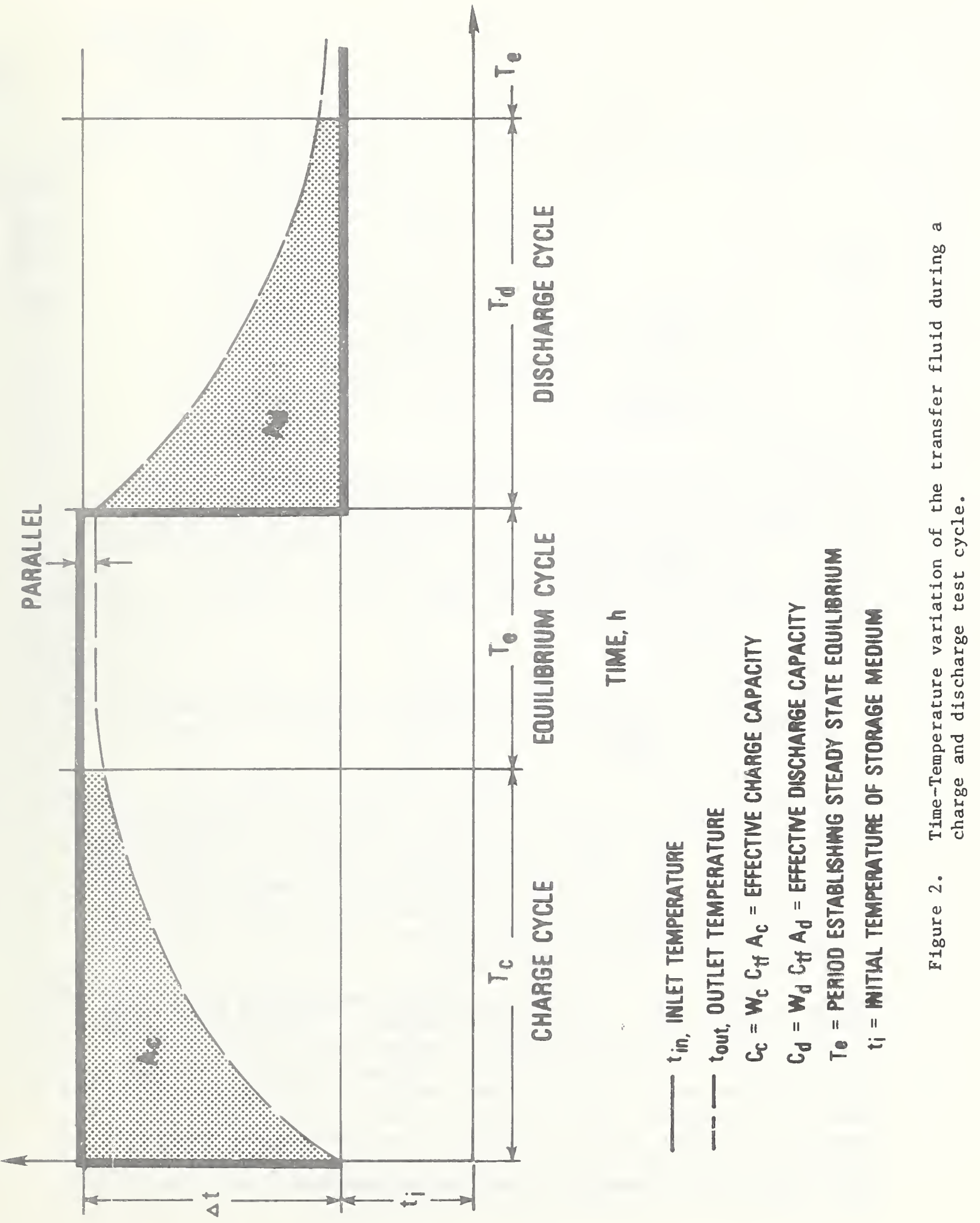

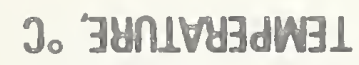




$$
c_{d}=w_{d} c_{t f} \int_{\tau=0}^{\tau=\tau_{d}}\left(t_{\text {out }}-t_{\text {in }}\right) d \tau
$$

where,

$$
\begin{aligned}
& \mathrm{C}_{\mathrm{c}}=\begin{array}{l}
\text { charge capacity of the thermal storage device, } \\
\mathrm{J} \text { (Btu) }
\end{array} \\
& \mathrm{C}_{\mathrm{d}}=\text { discharge capacity of the thermal storage device, } \\
& \mathrm{J} \text { (Btu). }
\end{aligned}
$$

Observe that in the computations for the charge capacity, the quantity of heat loss occurring over the test period, ' ${ }_{c} c$, is accounted for in the right hand portion of equation (6). This term does not appear in equation (7) since energy is being extracted from the device over the test time, $\tau_{d}$. Also observe that the charge capacity is a function of the specific heat of the transfer fluid. This makes the rating of the device dependent on the fluid used.

\section{NBS TEST FACILITY}

The tests conducted and described in this report were performed on a 1.9 $\mathrm{m}^{3}$ ( $500 \mathrm{gal}$ ) water tank which is built into a complete solar heating and cooling system at NBS.

NBS has been experimentally investigating the performance of whole buildings and their heating systems since 1940, when its first environmental chamber was completed. In the early $1970^{\prime} s$, a prefabricated townhouse with a floor area of $110 \mathrm{~m}^{2}\left(1200 \mathrm{ft}^{2}\right)$ was purchased on the open market and installed in a large $2100 \mathrm{~m}^{3}\left(70,000 \mathrm{ft}^{3}\right)$ environmental chamber. Environment-controlled tests were performed and the results were used to verify an NBS-developed computer program for estimating the heating and cooling loads of buildings [9, 10].

During 1974, the house was relocated onto the NBS grounds and a solar heating and cooling system was retrofitted to it. The system consists of $45 \mathrm{~m}^{2}$ ( $485 \mathrm{ft}^{2}$ ) of double-glazed, flat-plate water-heating solar collectors, $5.7 \mathrm{~m}^{3}$ (1500 gal) of water storage, a $10,000 \mathrm{~W}$ ( $3 \mathrm{ton}$ ) lithium bromide absorption air cooling unit and a $17.6 \mathrm{~kW}$ electric boiler. The plumbing is quite complex to allow for the versatility needed in performing various controlled tests (see Figures 3 and 4). The house was also fitted with a highly versatile data acquistion system (DAS). The house is capable of being either manually controlled or operated completely by the DAS. The DAS consists of: 


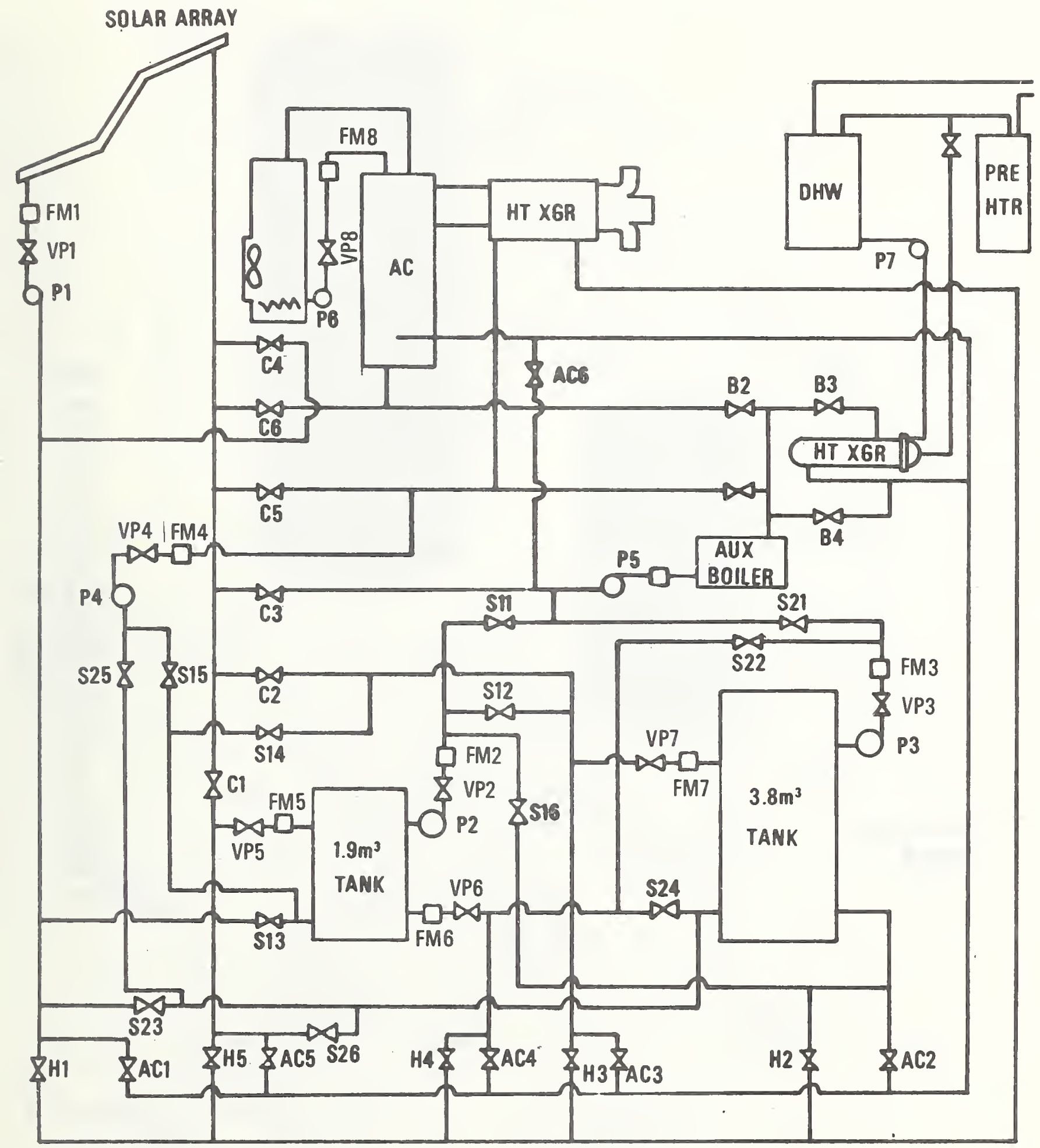

Figure 3. Plumbing schematic of the NBS solar townhouse facility. 
1. a six-digit integrating digital voltmeter,

2. a scanner permitting the voltmeter to read any of 400 channels of data,

3. a magnetic tape system to record measured values,

4. four data source input channels that allow the input of binary coded decimal information,

5. a relay register with 48 separate contacts that enable the system to control external measuring devices as well as pumps, motors, valves, etc., that comprise the solar system, and

6. a mini-computer which serves as the control for the total system.

The entire house and the solar system is fitted with various temperature and physical property sensors, all of which are wired to the DAS.

As shown in Figures 3 and 4, the solar system consists of $3.8 \mathrm{~m}^{3}$ (1000 gal) and $1.9 \mathrm{~m}^{3}$ (500 gal) water storage tanks interconnected with the solar collectors via an elaborate plumbing system. These tanks were fabricated of ASME flange-quality steel, are unlined, and are available on the open market. They were manufactured in a manner enabling the transfer fluid to enter or exit the containers at any given $0.61 \mathrm{~m}$ ( $2 \mathrm{ft}$ ) elevations by means of hand-operated valves (see Figures 5 and 6). The tanks are covered with $10.2 \mathrm{~cm}$ ( $4 \mathrm{in}$ ) of glass fiber insulation, fitted with type-T thermocouple temperature sensors at $0.36 \mathrm{~m}$ ( $1 \mathrm{ft}$ ) elevations wi thin the tanks, and are exposed to the ambient in an equipment room. The storage medium within the containers is water with a 40 percent concentration of ethylene-glycol. Insignificant quantities of corrosion inhibitors are also present.

The ASHRAE Standard 94-77 test procedure was performed on the $1.9 \mathrm{~m}^{3}$ ( $500 \mathrm{gal}$ ) tank only. The $3.8 \mathrm{~m}^{3}$ (1000 gal) tank was used as a reservoir to supply the necessary transfer fluid at the required temperature to the smaller tank. Type-T thermocouple temperature sensors present at the inlet and the outlet of the tanks were used in recording the transfer fluid temperatures at the respective locations throughout the tests.

Six different positive-displacement flow meters we re used in monitoring the transfer fluid mass flow rates. These meters were equipped with pulse generators producing electronic outputs which we re received and displayed by light-emitting diode pulse counters. Each counter was wired to the minicomputer thus enabling the operator to' automatically read and record accumulated flow data at predetermined intervals. 


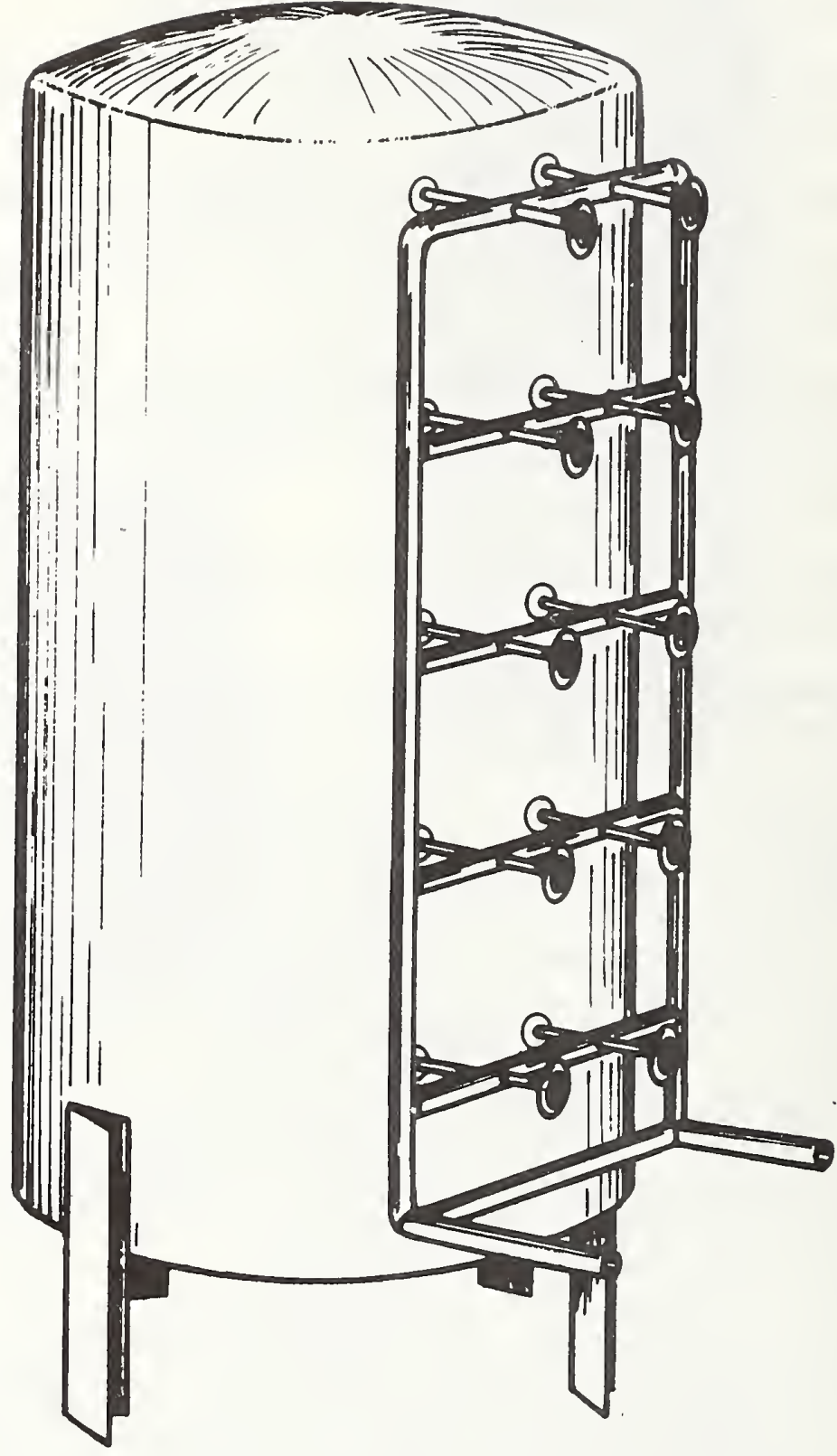

Figure 5. Isometric representation of the $1.9 \mathrm{~m}^{3}$ (500 gal) water tank in the NBS solar townhouse facility. 

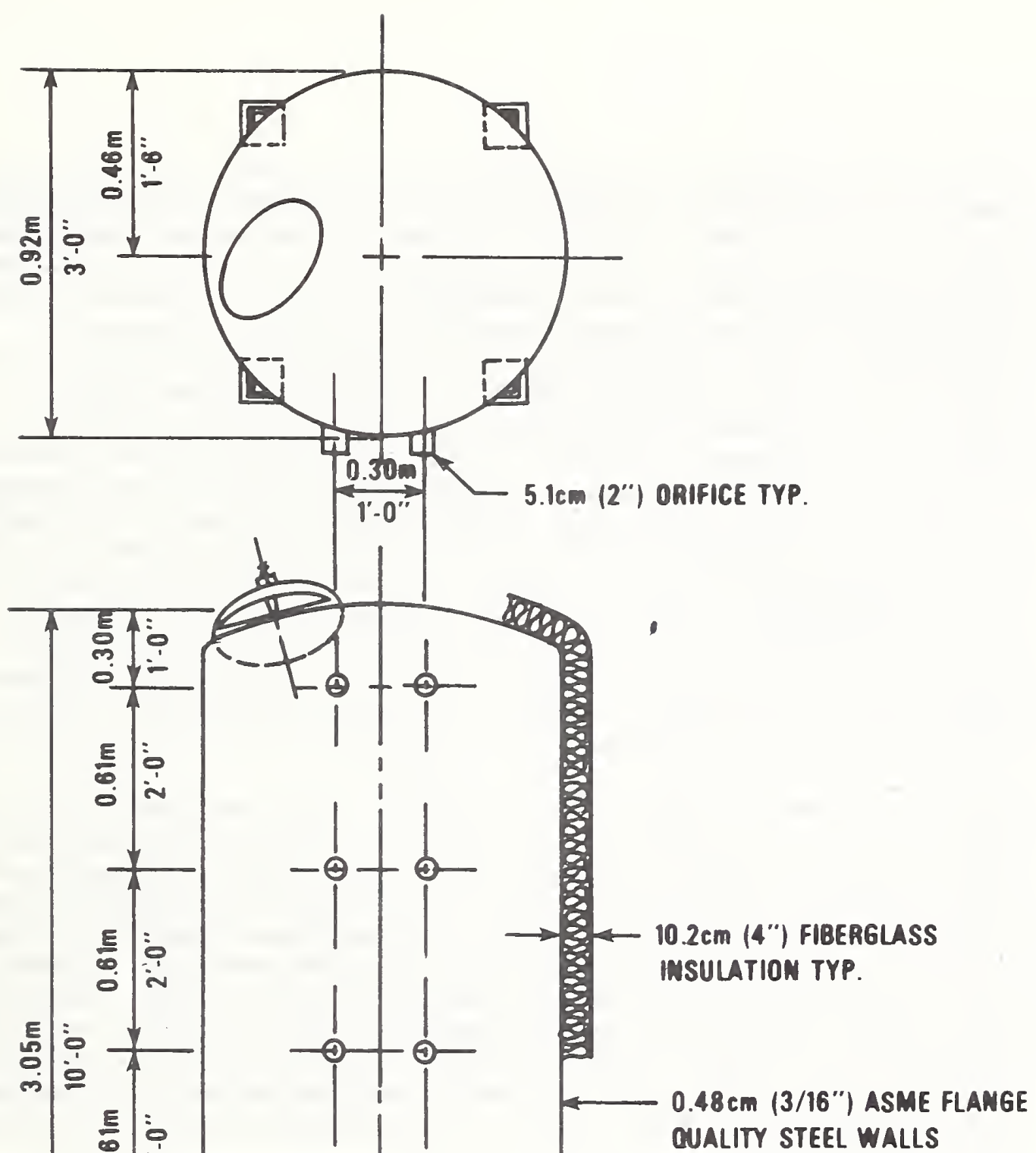
OUALITY STEEL WALLS STEEL HEAD TYP.

Figure 6. Schematic representation of the $1.9 \mathrm{~m}^{3}$ (500 gal) water tank in the NBS solar townhouse facility. 
Prior to all testing, the various type-T thermocouples used for the temperature difference measurements were calibrated. The calibration was done in two steps. In the first step, the sheathed thermocouple probes were removed for the test facility and calibrated by the NBS Temperature Measurements and Standards Division in a constant-temperature both against a secondary standard (platinum resistance thermometer). After the probes were replaced in the storage tank test loop, a second calibration check was made to insure that for matched pairs of the thermocouples, the uncertainty in temperature difference measurement would be within $+0.1^{\circ} \mathrm{C}\left( \pm 0.2^{\circ} \mathrm{F}\right)$ as required by Standard 94-77. An apparatus consisting of solid dowels submerged in a highly viscous oil within a glass thermos was used. The various thermocouples were $\mathrm{pl}$ aced into the oil and the temperature of the copper-oil medium raised by means of an electrical resistance heater. Various temperature levels encompassing the intended test range were obtained and the DAS was used to print-out the temperatures sensed per thermocouple. It was found that all temperature difference discrepancies we re within the $\pm 0.1^{\circ} \mathrm{C}\left( \pm 0.2^{\circ} \mathrm{F}\right)$ uncertainty range. Therefore, no data corrections were applied.

The DAS was used to calculate the necessary data and store it on magnetic tape. An associated line printer was used to obtain that part of the data required for test calculations. A thermocouple indicator was also wired to various thermocouple temperature sensors throughout the system. By operating a manual switch, any of the pertinent temperature sensors could be observed. This thermocouple indicator proved to be most conducive to monitoring the desired temperature of the inlet transfer fluid. A two-channel strip chart recorder was also wired into the DAS to monitor the transfer fluid inlet and outlet temperatures. The recorder generated an excellent graphical representation of the inlet and outlet fluid temperatures. These plots are representative of what was occuring during the tests. 


\section{EXPERIMENTAL PROCEDURE}

Heat Loss Test:

The heat loss test was carried out in accordance with the Standard. The DAS was set up to perform a scan every 15 seconds of the various sensors involved. Those sensors vital to the heat loss computations consisted of the transfer fluid inlet and outlet temperatures, the storage medium temperature, the ambient air temperature, and the fluid flow rate.

The transfer fluid was circulated through the thermal storage device (SI) and through the auxiliary boiler (ON) (see Figure 7). The mass flow rate was adjusted and set to a value determined by equation (2). This was done by adjusting variable proportional valves VP 2 and VP6. The boiler was used to raise the inlet transfer fluid temperature to a value of $25^{\circ} \mathrm{C}\left(45^{\circ} \mathrm{F}\right)$ above the average air ambient temperature, $t_{a}$. The ambient temperature sensors were located at one-foot increments from the floor to ceiling within the equipment room. The DAS printed out a complete listing of these temperatures and also the average ambient temperature. Once steady-state conditions were reached and maintained for a one-hour period, all data were recorded.

For comparative purposes, a stagnant heat loss test was performed on the thermal storage device. This test was not designated or recommended in the Standard. The temperature of the storage medium was raised in a similar manner with the auxiliary boiler to a value of $65^{\circ} \mathrm{C}\left(149^{\circ} \mathrm{F}\right)$. The fluid was circulated at the flow rate defined by equation ( 2 ) until steady-state conditions at a uniform $65^{\circ} \mathrm{C}\left(149^{\circ} \mathrm{F}\right)$ we re obtained. Once this state was reached, the inlet and outlet portals to the thermal storage device we re sealed of $\mathrm{f}$

The device was allowed to cool off over a period of 48 hours while ambient air and storage medium temperatures were being recorded. Figure 8 depicts this temperature history. The figure clearly shows a repetitive rise and fall in the ambient air temperature during the day and night hours, respectively. The data were utilized for calculating the amount of heat loss per hour and a heat loss factor was calculated and compared to that value determined in accordance with the Standard.

\section{Transient Charge Tests}

For the transient tests performed, the recommended values for step temperature change, $\Delta t$, and fill times, $\tau_{f}$, we re used. Additional tests were also conducted for other values of the test parameters and a complete list for all charge and discharge tests is given in Table 1.

The transfer fluid was circulated through the storage device $\left(1.9 \mathrm{~m}^{3}\right.$ (500 gal water tank)) until steady-state conditions were established. The value of the initial temperature, $t_{i}$, was chosen based on the known application of the device in accordance with the instructions in the Standard. Figure 9 depicts the range chosen for these tests. 


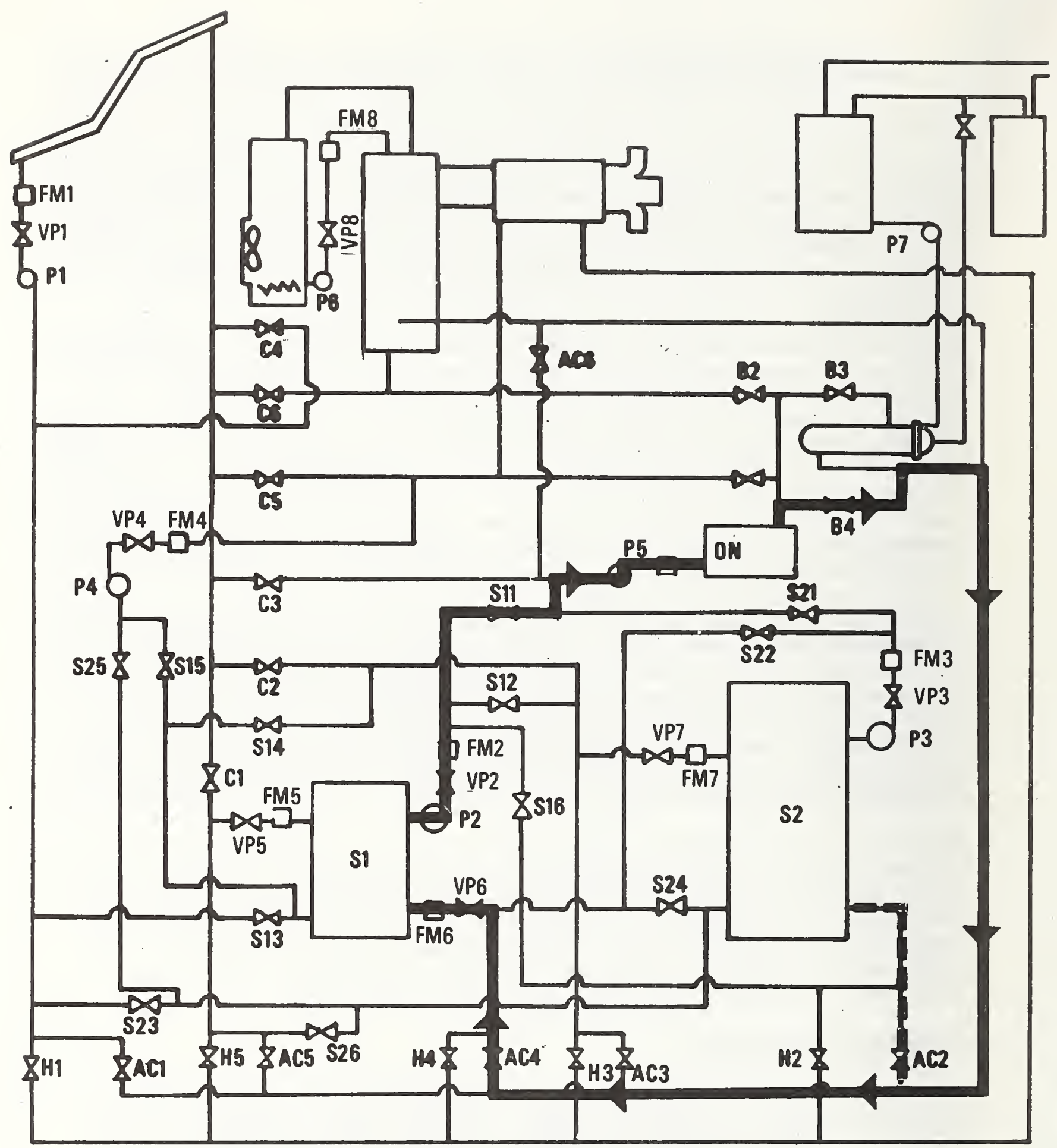

Figure 7. Charging the small storage tank with the auxiliary boiler. 


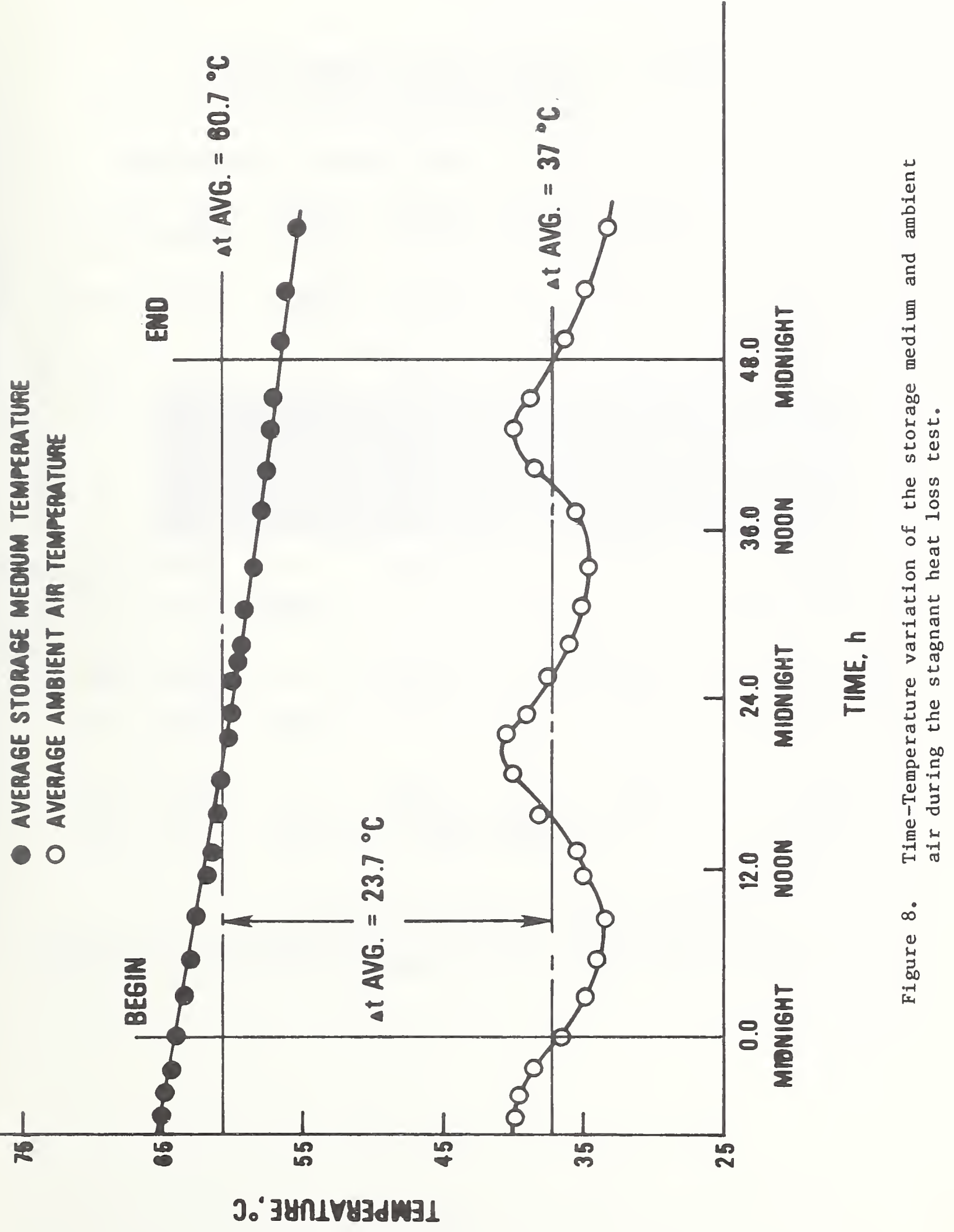


Table 1. Transient test parameters used for the charge and discharge tests.

Fill Time Mass Flow Rate Temperatures

Charge Discharge Charge Discharge Step Initial Test Test Test Test Change

TEST

DESCRIPTION

Charge*

Discharge*

Discharge**

Charge*

Discharge*

Charge

Discharge

Charge

Discharge $\tau_{c}(h)$

$\tau_{d}(h)$

$w_{c}(k g / s)$

$w_{d}(k g / s)$

$\Delta t\left({ }^{\circ} \mathrm{C}\right)$

$t_{1}\left({ }^{\circ} \mathrm{C}\right)$

2. 0

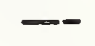

0.259

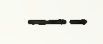

15.3

43

$--$

2.0

$-\infty$

0.259

13.4

53

$--$

2.0

$-$

0.251

14.7

67

4.0

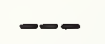

0.130

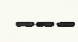

15.4

41

$-\infty \quad 4.0$

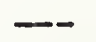

0.129

14.4

57

1.0

$-$

0.531

$-$

15.3

38

$--\quad 1.0$

-

0.528

16.8

49

0.55

$--$

0.951

$-$

13.8

38

0.55

0.951

12.6

69

* Recommended ASHRAE Standard 94-77 values.

** Cool inlet transfer fluid introduced into top of the water tank. 


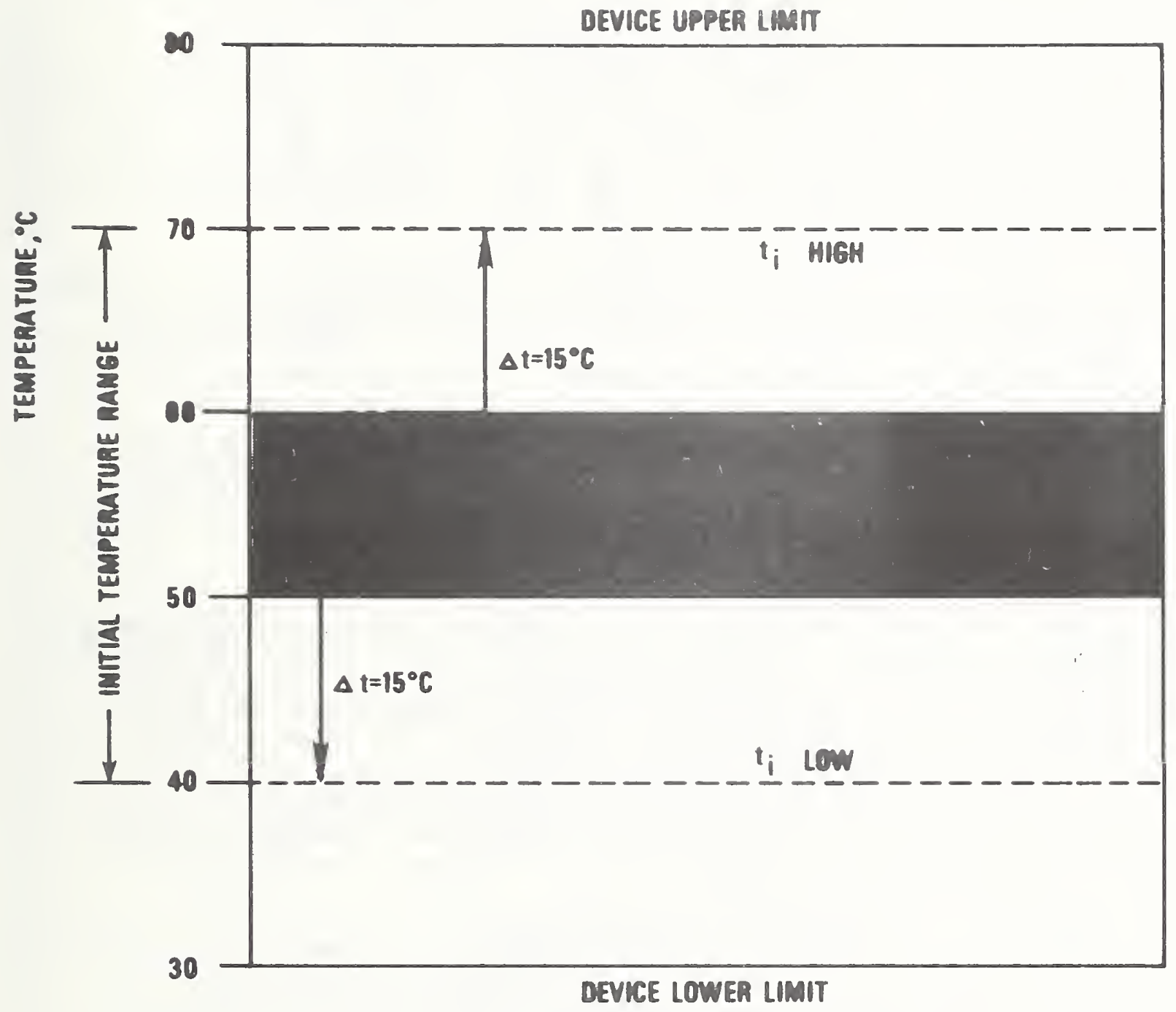

Figure 9. Test temperatures used for the charge and discharge test. 
It can be seen that the device has a designated upper limit of $80^{\circ} \mathrm{C}\left(176^{\circ} \mathrm{F}\right)$ and a lower 1 imit of $30^{\circ} \mathrm{C}\left(76^{\circ} \mathrm{F}\right)$. It has been found that the storage medium temperature is usually within the range of $50^{\circ} \mathrm{C}$ to $60^{\circ} \mathrm{C}\left(122^{\circ} \mathrm{F}\right.$ to $\left.140^{\circ} \mathrm{F}\right)$ during typical system operation. Therefore, this range, in conjunction with the recommended $15^{\circ} \mathrm{C}\left(27^{\circ} \mathrm{F}\right)$ temperature step was utilized in determining the limits as shown in the Figure $\left(40^{\circ} \mathrm{C}\right.$ and $70^{\circ} \mathrm{C}\left(104^{\circ} \mathrm{F}\right.$ and $\left.\left.158^{\circ} \mathrm{F}\right)\right)$. The higher limit was used as the initial temperature in the discharge test and the lower limit used as the initial temperature in the charge tests. These values were only approximate; the exact values are given in Table 1.

It is noted that, in reference to Figure 2, a single charge and discharge test are shown to be performed in series with each other. During this test program, the transient tests were performed in a different manner due to the way the system was configured. Two options were available to achieve and maintain the required transfer fluid temperature step increase. One method was to follow the plumbing loop shown in Figure 7 and use the auxiliary boiler to obtain the necessary step increase in the inlet temperature. The second option was to utilize the flow pattern shown in Figure 10 and pump fluid at $t_{i}+\Delta t$ from the $3.8 \mathrm{~m}^{3}$ ( $1000 \mathrm{gal}$ ) storage device to the $1.9 \mathrm{~m}^{3}$ (500 gal) device.

The former method using the auxiliary boiler was not successful in maintaining the required temperature step increase, $t_{i}+\Delta t$. A variable alternating current transformer was wired to one of the five electrical resistance elements in the boiler. This configuration was not sensitive enough to maintain a constant temperature step. The inlet transfer fluid temperature fluctuated above and below the desired $t_{i}+\Delta t$ due to the time lag of the heating element. Once the operator detected a drop in the inlet temperature from the intended $t_{i}+\Delta t$, an increase in current to the heating element usually resulted in an overshoot of the desired temperature step, $t_{1}+\Delta t$.

The second method was found to be quite successful and was therefore fully utilized for all transient tests performed. The procedure consisted of raising the temperature of the storage medium in the $3.8 \mathrm{~m}^{3}$ (1000 gal) storage device to a value above the desired temperature step $t_{i}+\Delta t$. This was generally accomplished by using the solar collector panels and circulating the transfer fluid as shown in Figure 11 during the daylight hours. The auxiliary boiler was utilized when solar energy was not avaialble. In order to maximize the utility of the system, the large storage tank was heated to a value above the initial temperature of the small tank, usually slightly more than $t_{1}+2 \Delta t$. This allowed two charge tests to be performed in series and saved both experimental time and auxiliary energy.

Once the large storage tank medium was heated to a desired value, both storage devices were isolated as depicted by Figure 12 and their respective transfer fluids circulated until steady-state conditions we re established. This was necessary for the small tank, in accordance with the Standard, and also for the large tank, since any temperature stratification in the large tank would disrupt the desired step increase once the transfer of fluid was initiated from the large tank to the smaller tank. 


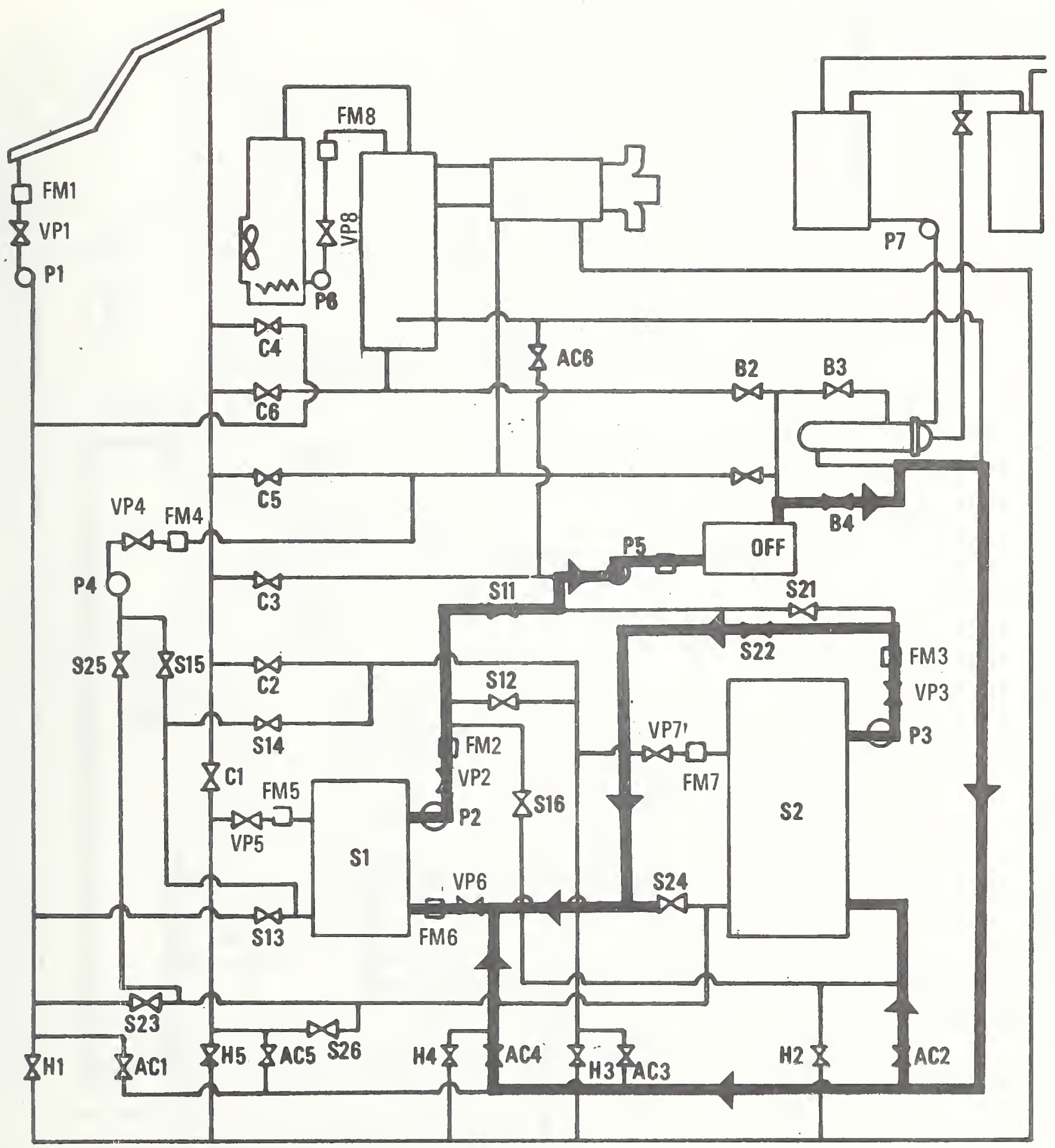

Figure 10. Charging (Discharging) the small storage tank with higher (lower) temperature fluid from the large tank (boiler not in use). 


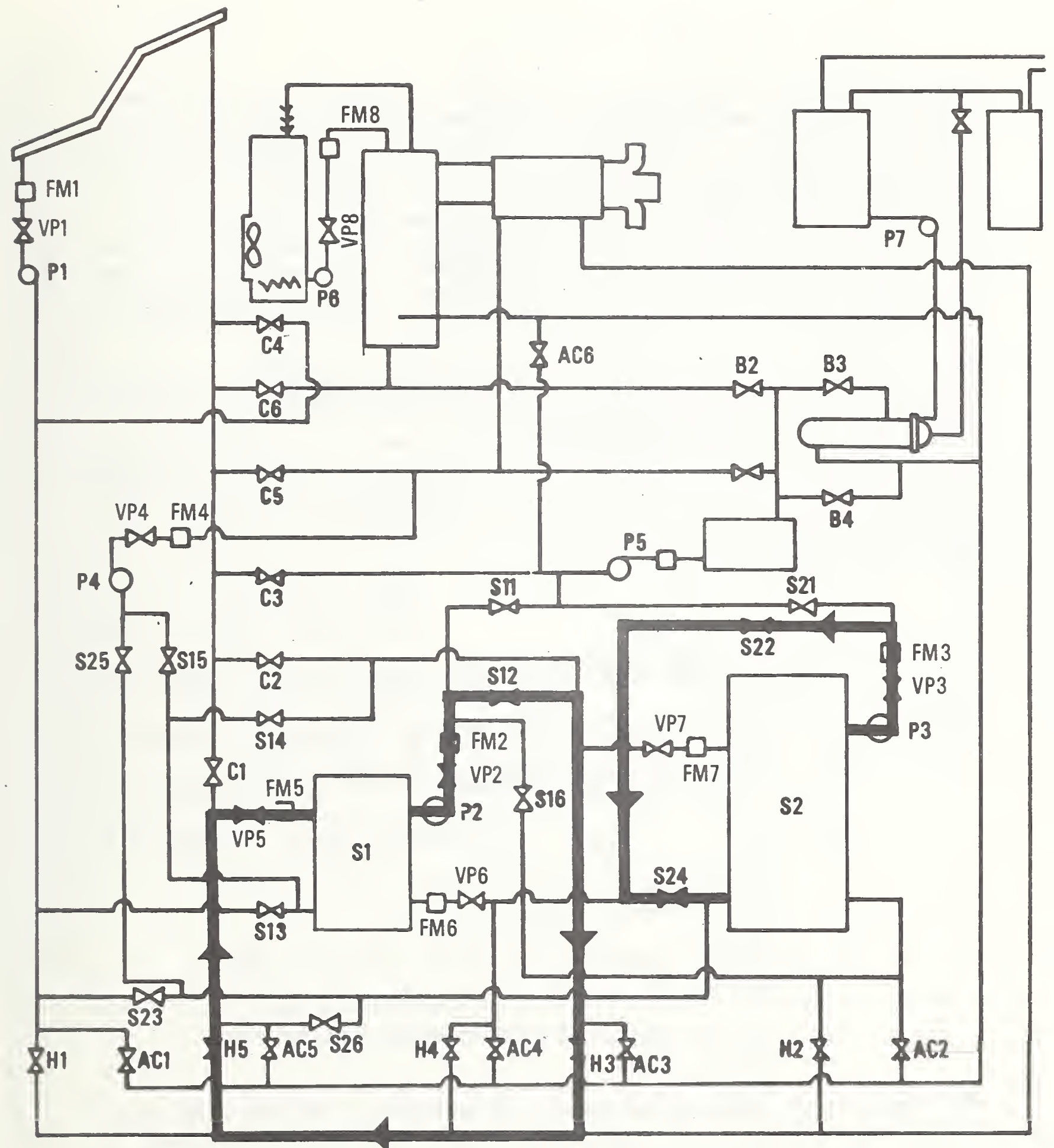

Figure 12. Obtaining steady-state conditions in both storage tanks prior to the start of any transient test by circulating the fluid in a closed loop. 
While steady-state conditions were being established in the small tank, equation (4) was used to determine the mass flow rate of the transfer fluid. The setting of this rate was accomplished by controlling variable proportional valve VP2 (see Figure 12). While steady-state conditions were being established in the large tank, flow meter FM3 was monitored and the flow rate was regulated by proportional valve VP3. Since the reserve medium of the large tank was at a temperature above the desired step increase, a specific flow rate had to be established such that when mixed with the fluid from the smaller tank (see Figure 10), the desired temperature step to the small tank could be established and maintained.

Figure 13 indicates the mixing process involved in determining the known mass flow rate through FM3. The initial temperatures of both storage devices were known quantities and established for each test. The final temperature of the inlet transfer fluid was a known quantity equal to the initial temperature of the small tank plus the desired temperature step increase. The mass flow rate of the transfer fluid pumped through the small storage device was al so known and determined by equation (4). Referring to Figure 13, the following equation for the desired mass flow rate through FM3 can be derived:

$$
w_{1}=w_{f} \frac{\Delta t}{\left(t_{i 1}-t_{i 2}\right)}
$$

where

$$
\begin{aligned}
\mathrm{W}_{1}= & \text { exiting mass flow rate from the large tank, } \\
& (\text { through } \mathrm{FM} 3) \mathrm{kg} / \mathrm{s}(\mathrm{lb} / \mathrm{h}) \\
\mathrm{w}_{\mathrm{f}}= & \mathrm{w}_{\mathrm{c}, \mathrm{d}} \\
= & \text { entering mass flow rate of the transfer fluid } \\
& \text { into the small tank, } \mathrm{kg} / \mathrm{s}(1 \mathrm{~b} / \mathrm{h}) \\
\mathrm{t}_{\mathrm{il}}= & \text { initial temperature of the large tank storage } \\
& \text { medium, }{ }^{\circ} \mathrm{C}\left({ }^{\circ} \mathrm{F}\right) \\
\mathrm{t}_{\mathrm{i} 2}= & \text { initial temperature of the small tank storage } \\
& \text { medium, }{ }^{\circ} \mathrm{C}\left({ }^{\circ} \mathrm{F}\right) .
\end{aligned}
$$

The transient charge test was begun by transferring the large tank storage medium at its elevated temperature to the small tank (see Figure 10). For all charge tests performed, the inlet transfer, fluid was introduced into the top of the small storage tank and the exiting transfer fluid was removed from the bottom.* This represented the configuration in

* The schematic of Figure 10 may appear to misrepresent the proper entrance and exit locations. Refer to Figure 5 for true portal configuration. 


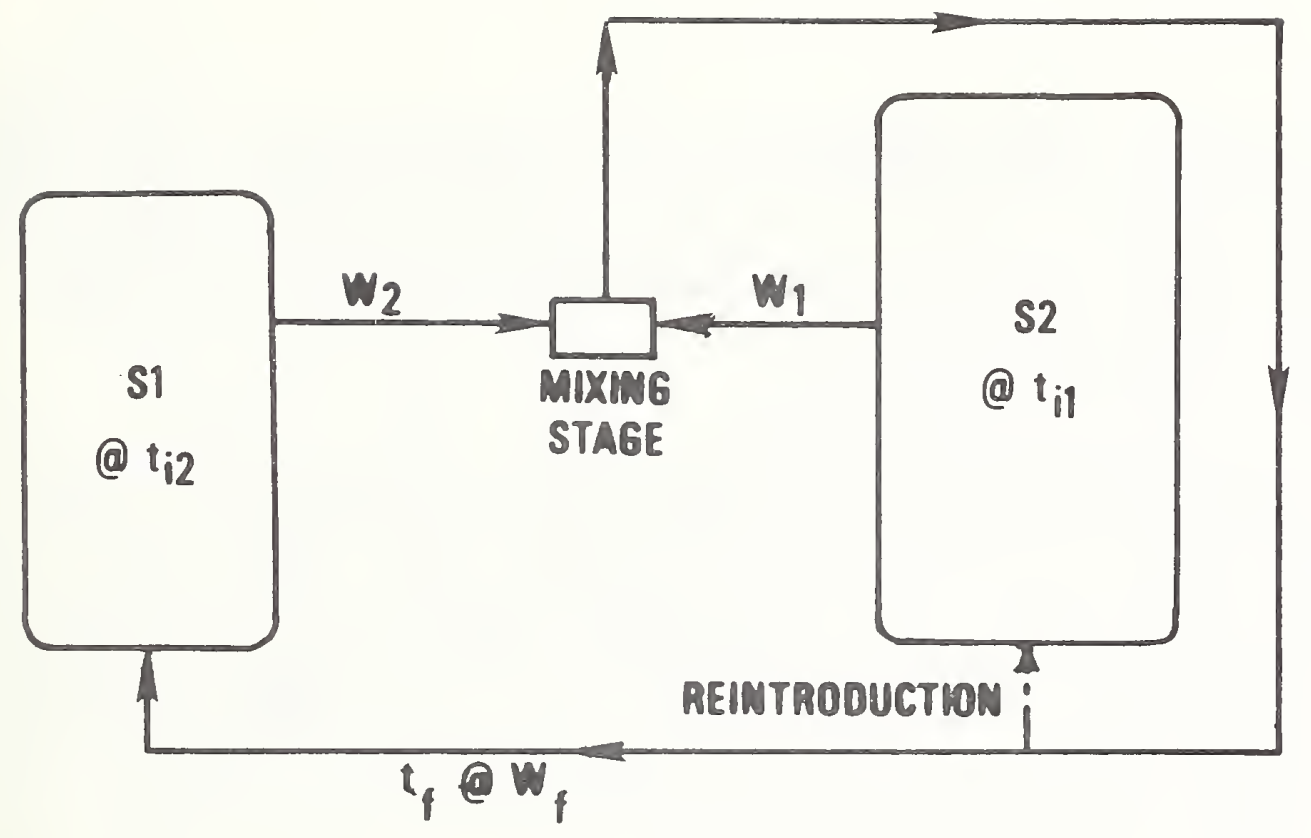

$S 1=1.9 m^{\prime 3}$ (500 GALLOW) TAWK

$S 2=3.8 \mathrm{~m}^{3}$ (NOO GALLON) TANK

$\mathrm{t}_{\mathrm{i}_{2}}=$ INITLAL STORAGE MEDUM TEMNERATUNE SMALL TANK, ${ }^{\circ} \mathrm{C}\left({ }^{\circ} \mathrm{F}\right)$

$t_{i 1}=$ MITHL STOAME MEOWM TEMNERTURE LARCE TAMK, ${ }^{\circ} \mathrm{C}$ ( ${ }^{\circ} \mathrm{F}$ )

$t_{f}=$ FWAL TMANSFER FLUD TEMPERATURE, ${ }^{\circ} \mathrm{C}$ ( ${ }^{\circ} \mathrm{F}$ )

$W=$ RESRECTME MASS FLOW RATES, $\mathrm{kg} / \mathrm{s}(\mathrm{mm} / \mathrm{h})$

Figure 13. Schematic representation of the required mixing process for the conduct of the transient tests. 
which the device would normally function within any solar system and was thus tested in this way. Once the transfer was initiated, a thermocouple indicator and strip-chart recorder were used to monitor the temperaturetime history of the charge cycle as depicted by the plots in Appendix A. A print-out from the DAS in real time was also used during the tests, while all pertinent data were stored on the magnetic tape for future retrieval and reduction.

While the transient charge test was being executed, strict observation of the outlet transfer fluid temperature profile was necessary. The only change during the test execution was the regulation of the flow rate, $W_{1}$, through FM3. As the test proceeded, the storage medium of the small tank stratified with the higher temperature strata at the tank top where the hotter transfer fluid was being introduced. However, when enough time elapsed to allow the higher temperature strata to permeate to the lower elevations of the small tank and begin exiting, the amount of transferred energy from the large tank was reduced; otherwise, the inlet transfer fluid temperature to the small tank would rise above the temperature step increase required for the test.

Therefore, the flow rate through FM3 was progressively reduced as the test proceeded by manual control of VP3.

\section{Transient Discharge Tests}

The procedure for the performance of the transient discharge tests was identical to that utilized for the charge tests in that the large tank was used as a reservoir of low temperature fluid and the flow arrangement indicated in Figure 10 was used in performing the tests. The temperature of the large tank storage medium was lowered to a value enabling a series of discharge tests to be performed, thus maximizing the utility of the system as was discussed previously. This usually led to lowering the storage medium to a value of at least $t_{i}-2 \Delta t$, where $t_{i}$ is the initial temperature of the small tank storage medium.

The lowering of the large tank medium temperature was accomplished by circulating the fluid as shown in Figure 14 through the liquid-to-air heat exchanger within the house and through the solar array during the night hours. It was found that by allowing this process to take place during the entire night hours, the large tank storage mediun would be at a state of adequately low temperature to allow for a series of discharge tests to be conducted the next day. It is also noted that this condition was facilitated by performing the charge tests in series during the day and allowing the cool-down to take place at night, thus yielding a large tank reserve of low temperature fluid and a small tank of high temperature fluid the following day.

As with the charge tests, steady-state conditions and the setting of the proper flow rates were established during the period when the two tanks were isolated as depicted in Figure 12. Equation (8) was utilized in establishing the proper flow rate through FM3. Once the flow rates and 


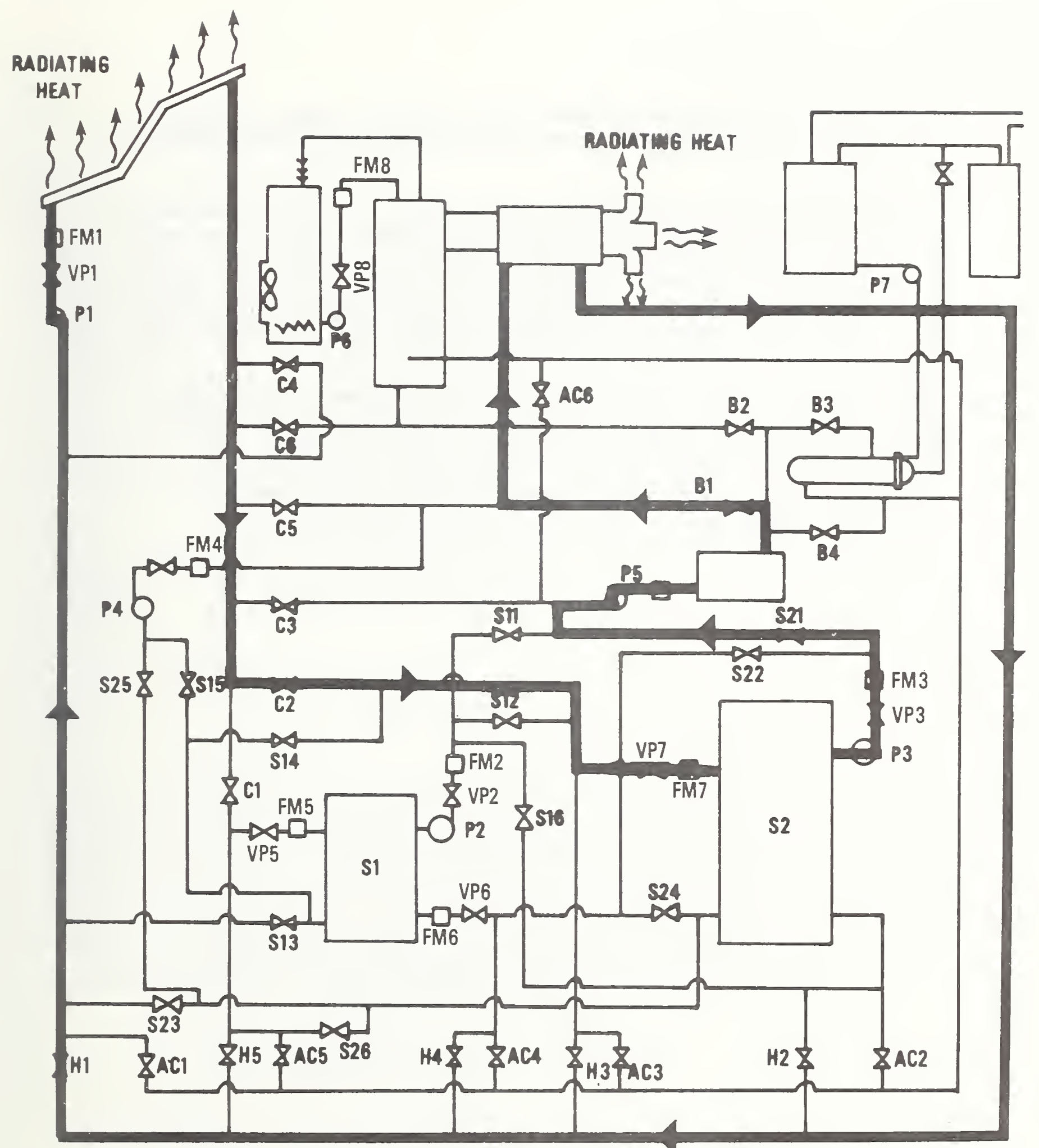

Figure 14. Dicharging the large storage tank during night hours via the liquid-to-air heat exchanger in the test house and the solar collector array. 
proper temperature were established, the transfer of fluid in the same mixing mode as for the charge tests was initiated for the discharge tests (see Figure 10).

For all discharge tests except one, the transfer fluid was introduced to the cool bottom strata of the small tank and exited from the top warmer strata. Once again, this represented a typical operating mode of the thermal storage device being tested. One discharge test was performed by introducing the colder inlet transfer fluid into the top of the small tank. This mode of operation minimizes stratification tendencies and causes a more thoroughly-mixed water tank.

As was experienced with the charge tests, the flow rate through FM 3 had to be reduced as the test proceeded. The outlet transfer fluid temperature would eventually become lower so that the amount of lower temperature fluid being introduced from the large tank had to be reduced. Once again, this was accomplished by the operator monitoring the inlet and outlet transfer fluid temperatures via the available equipment. 
Data Acquisition System

The DAS was programmed to perform a scan of all the temperature sensors every 15 seconds and record the temperatures on magnetic tape. Since the data made available via the 15 second scan were not always necessary for the data reduction process, the DAS was programmed to perform a printing of data blocks during the retrieval process at an interval representative of the test being executed. That is, for tests involving long charge and discharge periods, ${ }^{{ }} c, d$, the print-out interval would be greater than for tests involving shorter $\tau_{c}, d$ periods. In case any one of the sensors involved indicated a sudden rise or $\mathrm{fall}$ in temperature to the nearest tenth of a degree, the DAS was programmed to give an immediate print-out of that sensor and the temperature indicated, irrespective of the print-out period utilized in the retrieval process.

For the three types of tests performed (heat loss, charge and discharge), all were performed to determine quantities defined by equations (1), (6), and (7). Each of these equations has an integral term of the general form:

$$
\int_{0}^{\tau}\left(t_{i n}-t_{\text {out }}\right) d
$$

If a plot were made of the difference in transfer fluid inlet and outlet temperatures versus time over the test period, $\tau$, d the resulting curve would be as shown in Figure 15. The integral of équation (9) represents the area under such a curve. Throughout the test period, the DAS recorded the difference in the inlet and outlet transfer fluid temperature for each scan performed and summed these differences yielding the value of the integral. The DAS was also utilized in calculating the instantaneous and average value of the following heat loss term which appears in the right hand portion of equation (6):

$$
\left(t_{i}+\frac{\overline{t_{\text {in }}-t_{\text {out }}}}{2}-t_{a}\right)
$$

Heat Loss Test

The heat the heat loss factor defined by the ASHRAE Standard in equation (1) is: 

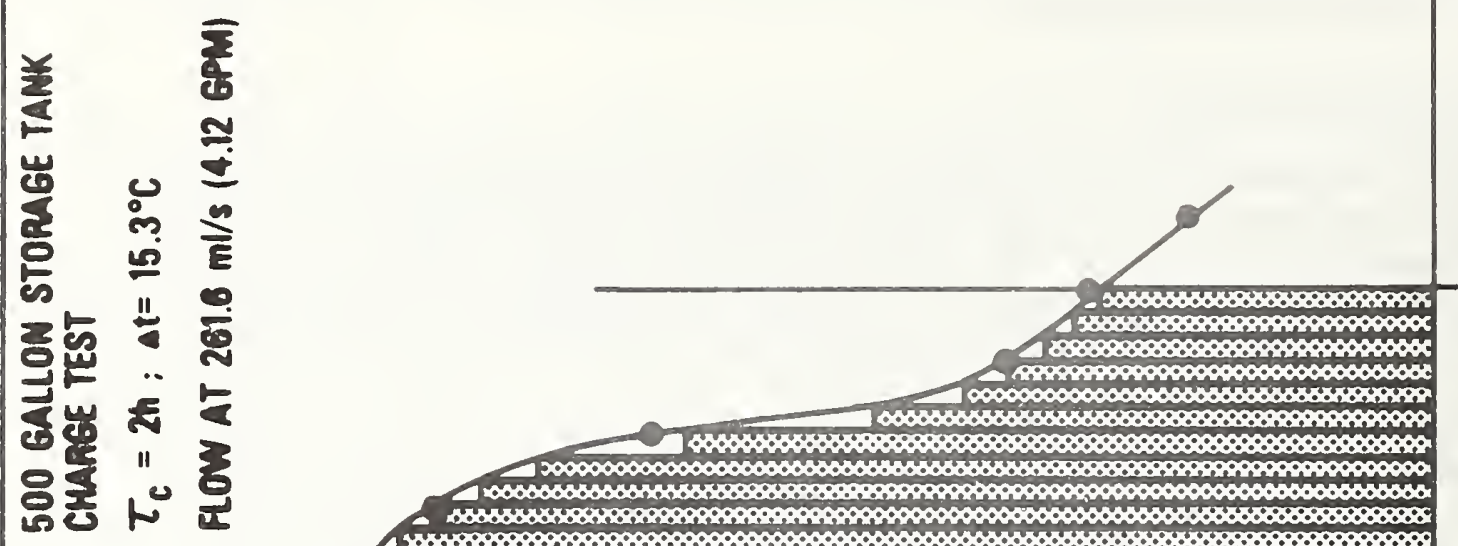

웅

- $1.0 .00 \%$ minter $\because \cdots \cdots$ (1) Dowow.

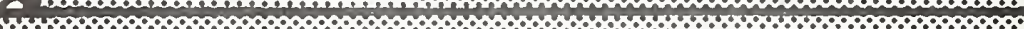
1.

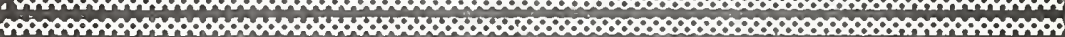

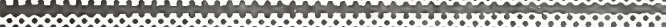

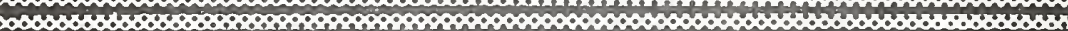

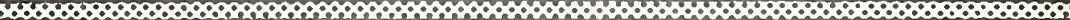

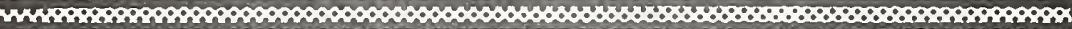

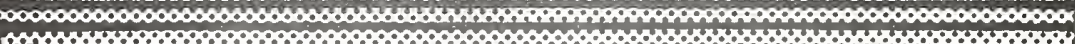

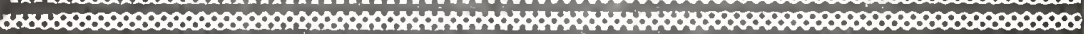

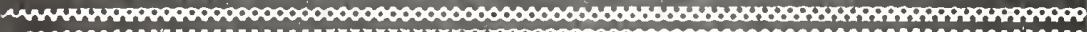

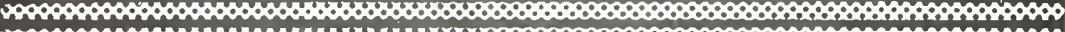

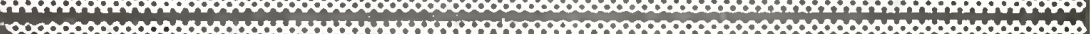

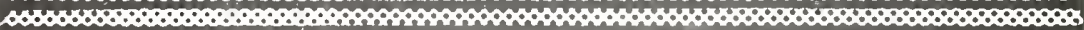

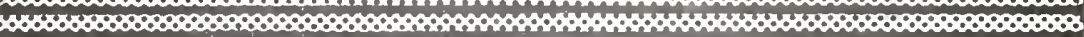
-

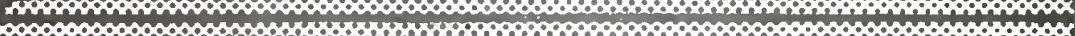

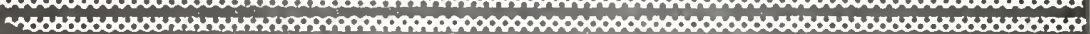

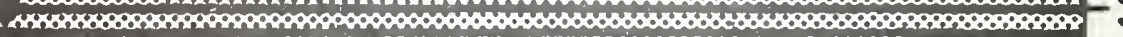

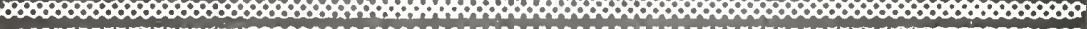

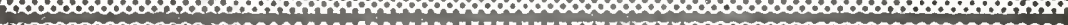

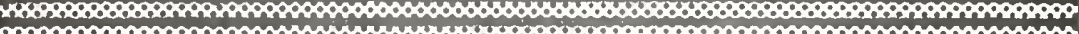

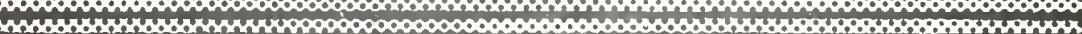

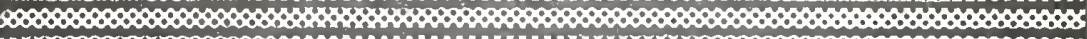

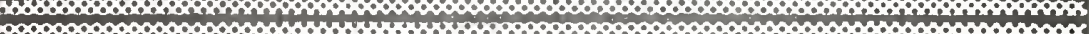

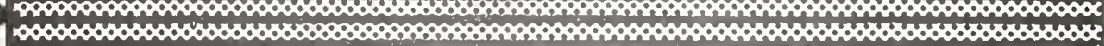

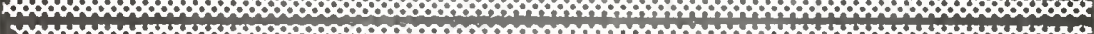

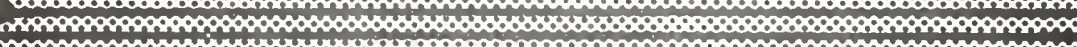

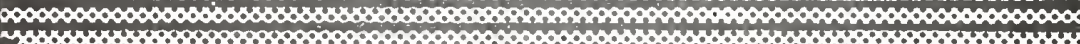


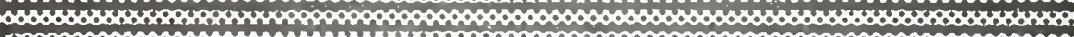

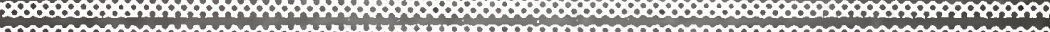

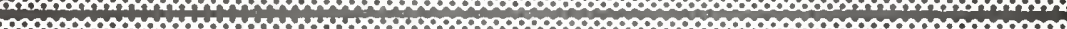
F.

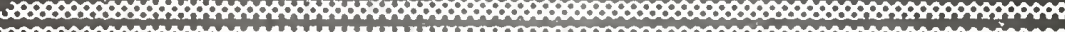
nip

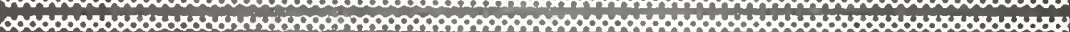

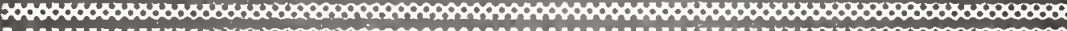

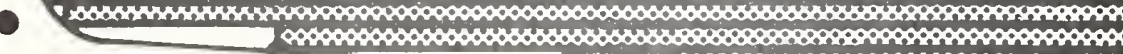

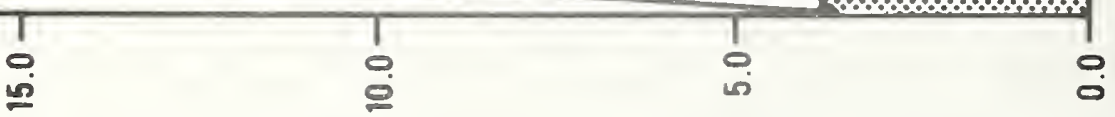

20: $\left(\frac{14}{4}-!\right)$ 


$$
L=\frac{w_{L} c_{t f}}{(3600 s)\left(25^{\circ} \mathrm{C}\right)} \int_{\tau=0}^{\tau=3600}\left(t_{\text {in }}-t_{\text {out }}\right) d \tau
$$

The specific heat of the transfer fluid was determined by sampling the storage medium with a hydrometer and establishing that there was a $40 \%$ ethylene-glycol concentration. Referring to the ASHRAE Handbook of Fundamentals [12], ethylene-glycol water solutions wi th a $40 \%$ concentration have a specific heat of $3,600 \mathrm{~J} /\left(\mathrm{kg}^{\circ}{ }^{\circ} \mathrm{K}\right)\left(0.85 \mathrm{Btu} /\left(1 \mathrm{~b}^{\circ}{ }^{\circ} \mathrm{F}\right)\right)$. By using this value with the DAS-computed value of the integral and the flow rate, $w_{L}$, the heat loss factor, $L$, defined by equation (1) was found to be :

$$
\mathrm{L}=16.16 \mathrm{~J} /\left(\mathrm{s} \cdot{ }^{\circ} \mathrm{C}\right)\left(30.61 \mathrm{Btu} /\left(\mathrm{h} \cdot{ }^{\circ} \mathrm{F}\right)\right) .
$$

As was mentioned previously, a stagnant heat loss test was also performed. Reference to Figure 7 depicts the temperature history profile of the storage medium and the ambient over the 48-hour test period. Using this data, the heat loss factor was calculated by:

$$
L=\frac{\dot{Q}}{\Delta t_{\text {avg }}}=\frac{Q \Delta \tau}{\Delta t_{\text {avg }}}=\frac{M_{\text {stg }} c_{\text {tf }} \Delta t_{\text {stg }}}{\left(\Delta t_{\text {avg }}\right) \Delta \tau}
$$

where,

$$
\begin{aligned}
\dot{Q}= & \text { rate of heat loss from storage medium, } \mathrm{J} / \mathrm{s}(\mathrm{Btu} / \mathrm{h}) \\
\Delta t_{\text {avg }}= & \begin{array}{l}
\text { average temperature difference between the storage } \\
\text { medium and the ambient over the test period, }{ }^{\circ} \mathrm{C}\left({ }^{\circ} \mathrm{F}\right)
\end{array} \\
\Delta \tau \quad= & \text { time period, } \mathrm{h} \\
M_{s t g}= & \text { mass of the storage medium, } 1890 \mathrm{~kg}(4165 \mathrm{lb}), \\
\Delta t_{s t g}= & \text { change in temperature of the storage medium over the } \\
& \text { test period, }{ }^{\circ} \mathrm{C}\left({ }^{\circ} \mathrm{F}\right)
\end{aligned}
$$

The value was found to be:

$$
\mathrm{L}=16.04 \mathrm{~J} /\left(\mathrm{s} \cdot{ }^{\circ} \mathrm{C}\right)\left(30.38 \mathrm{Btu} /\left(\mathrm{h} \cdot{ }^{\circ} \mathrm{F}\right)\right) .
$$


The two heat loss factors were in excellent agreement. The value used in the charge capacity calculations was that one determined in accordance with the Standard,

$$
\mathrm{L}=16.16 \mathrm{~J} /\left(\mathrm{s}^{\circ \circ} \mathrm{C}\right)\left(30.61 \mathrm{Btu} /\left(\mathrm{h}^{\circ \circ} \mathrm{F}\right)\right)
$$

It should be noted here that the calculation of the heat loss factor utilizing basic heat transfer theory and the material properties and dimensions of the thermal storage device and its insulation yielded a theoretical heat loss factor of:

$$
\mathrm{L}=5.67 \mathrm{~J} /\left(\mathrm{s}^{\circ{ }^{\circ} \mathrm{C}}\right)\left(10.75 \mathrm{Btu} /\left(\mathrm{h}^{\circ}{ }^{\circ} \mathrm{F}\right)\right) .
$$

The reason for the discrepancy between this value and the higher values determined experimentally is still being investigated.

\section{Transient Charge Tests}

The primary purpose of ASHRAE Standard 94-77 is for the determination of the "effective"* charge and discharge capacities of the thermal storage device being tested. The effective charge capacity has been defined by equation (6) to be:

$$
c_{c}=w_{c} c_{t f} \int_{\tau=0}^{\tau=\tau}\left(t_{\text {in }}-t_{\text {out }}\right) d \tau-L_{c}\left(t_{1}+\frac{t_{\text {in }}-t_{\text {out }}}{2}-t_{a}\right)
$$

Referring to equation (6), the known quantitles consist of the following:

1. the heat loss factor, $L$, determined above

2. the mass flow rate, $w_{c}$, calculated by equation (4)

3. the charge test fill time, $\tau_{c}$, specified by ASHRAE Standard 94-77 or calculated by equation (3) when the mass flow rate is inftially known, and

4. the specific heat of the transfer fluid, $c_{t f}$.

* So labelled effective since they represent only that portion of the capacities utilized over the time duration $\tau_{f}$. 
The first of the unknown quantities in equation (6) deals with the integral in the left-hand portion, identical to equation (9) and calculated by the DAS. The second of the unknown quantities in equation (6) deals with the right-hand portion, the heat loss over the charge period, $\tau_{c}{ }^{\circ}$ The major part of this term was calculated by the DAS as described previously.

Table 2 lists the various transient charge tests, the quantities of heat loss, and the "effective" charge capacities. It should be noted that, the quantity of heat loss was small compared to the quantity of energy stored in the device over the testing period.

Transient Discharge Test

The discharge capacity has been defined by equation (7) to be:

$$
c_{d}=w_{d} c_{t f} \int_{\tau=0}^{\tau=\tau d}\left(t_{\text {out }}-t_{\text {in }}\right) d \tau
$$

The same procedure for computing the effective charge capacity was applied for the computation of the effective discharge capacity. Table 2 also gives a complete listing of the results of these tests.

Data Analysis

ASHRAE Standard 94-77 suggests a plot be provided showing the time variation in transfer fluid temperatures for each test. Figure 16 shows such a plot for those tests involving the ASHRAE-recommended test fill times and temperature step changes. The abscissa represents time from $\tau=0$ to $\tau=\tau_{c, d}$, and the ordinate is a non-dimensional quantity defined by:

$$
\frac{t_{f, i}-t_{f, e}}{\Delta t}
$$

In equation (12), it is noted that the initial step change in transfer fluid inlet temperature, $\Delta t$, is a constant. However, the difference between the transfer fluid outlet and inlet temperatures decreases with time yielding the asymptotic curves of Figure 16. For a thermal storage device with perfect stratification and no heat loss to the ambient, the temperature of the inlet transfer fluid, $t_{f, i}$, and the outlet transfer fluid, $t_{f}, e$, would remain constant for the entire test period (time for one entire tank change), at which time they would become equal. A curve of test results for such a device would be represented by a rectangle. 
Table 2. Results of the transient tests performed on the $1.9 \mathrm{~m}^{3}$ (500 gal) water tank.

\begin{tabular}{|c|c|c|c|}
\hline $\begin{array}{c}\text { TEST } \\
\text { DESCRIPT ION }\end{array}$ & $\mathrm{C}_{\mathrm{c}}$ & $Q$ & $c_{d}$ \\
\hline Charge-2 & 9.29 & 0.16 & -- \\
\hline Discharge-2 & -- & -- & 7.63 \\
\hline Di scharge -2 * & -- & --- & 5.72 \\
\hline Charge -4 & 9.24 & 0.21 & -- \\
\hline Discharge-4 & $-\infty$ & $-\infty$ & 8.26 \\
\hline Charge-1 & 8.91 & 0.07 & $-\infty$ \\
\hline Discharge-1 & -- & -- & 9.49 \\
\hline Charge $-1 / 2$ & 8.03 & 0.06 & -- \\
\hline Di scharge-1/2 & - & -- & 7.11 \\
\hline
\end{tabular}

All units, Joules $\times 10^{7}$

*Cool inlet transfer fluid introduced into top of the water tank. Numerical identification following test description designates the test period involved, $\tau_{c}$ or $\tau_{d}$.

$C_{c}$ designates the "effective" charge capacity wi th heat loss accounted for.

$C_{d}$ designates the "effective" discharge capacity.

$Q$ designates the quantity of heat loss over the charge period. 


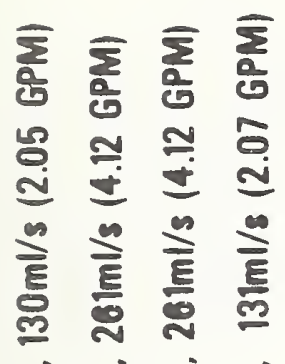

ن ن ن ن

\pm एक

" II II

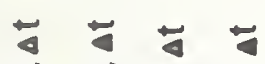

ธิ

"م"

- 0 -
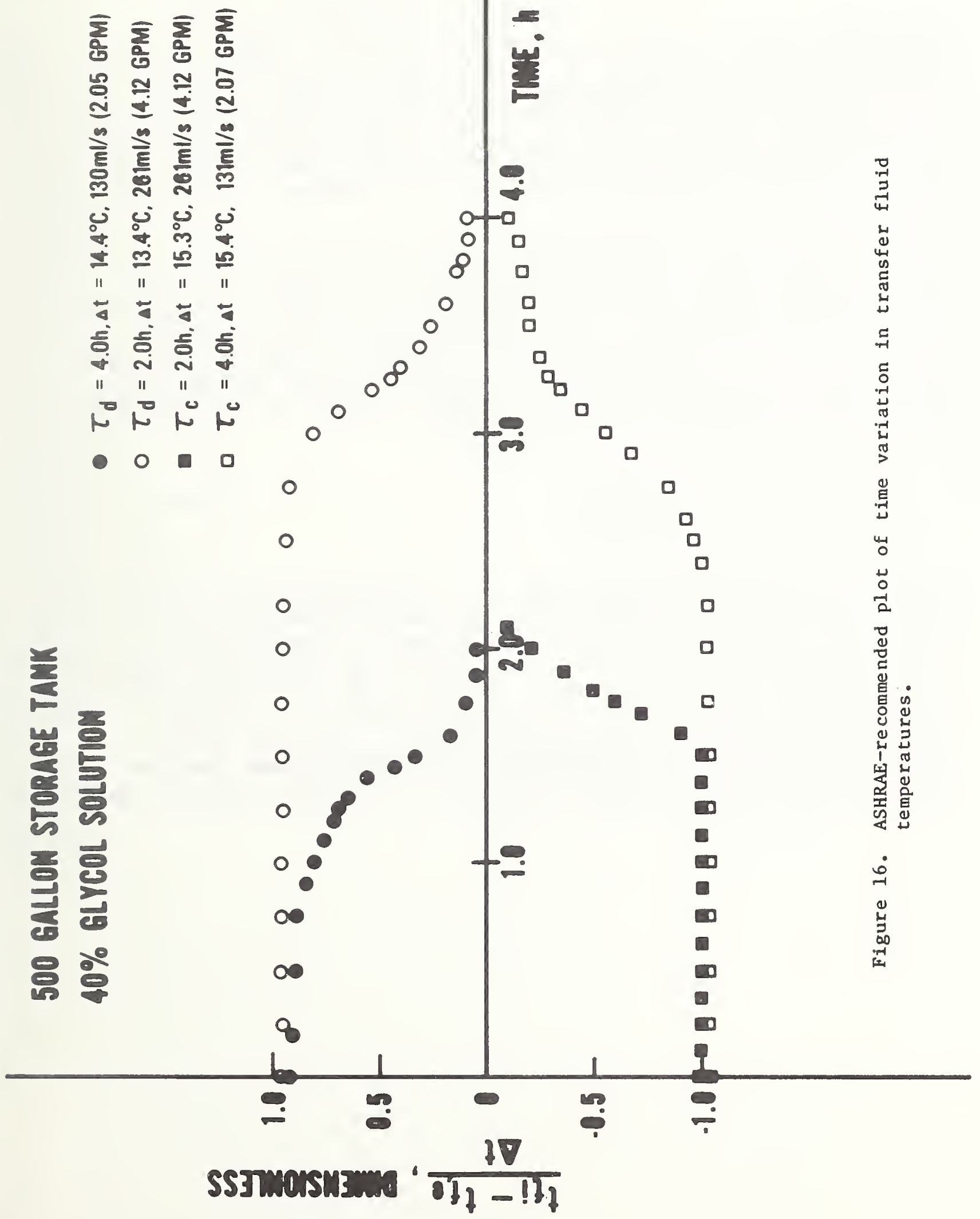
Other plots thought to be of value and not specified by ASHRAE Standard 94-77 are included in Appendix A. A plot of the inlet and outlet transfer fluid temperatures against time was prepared for each transient test. These plots are representative of those generated by the strip chart recorder used during the conduct of the tests. They distinctly show the temperature step increase or decrease in the inlet transfer fluid and the constant outlet temperature maintained up to some point late in the test period.

The concept of using a non-dimensional plot showing the thermal storage capabilities of storage devices relative to those of an ideal device has been proposed [5]. Suçh non-dimensional plots for each transient test performed on the $1.9 \mathrm{~m}^{3}$ (500 gal) storage device are found in Appendix B. The ordinate represents the difference between the inlet and outlet transfer fluid temperatures normalized by the step change in temperature, $\Delta t$, (identical concept utilized in Figure 16). The abscissa represents a non-dimensional time defined by:

$$
\frac{w_{t f} c_{t f \Delta t \tau}}{T S C}
$$

A value of non-dimensional time equal to 1.0 corresponds precisely to the test fill time or fluid dwell time of a perfectly-insulated, completely-stratified water tank. It is noted that the area under the curve on such a plot represents the amount of energy capable of being stored relative to the ideal device. Therefore, the area corresponding to the energy storage capability of the ideal device is 1.0 and all real devices have an area representatively smaller than 1.0 . Table 3 lists those transient tests performed on the thermal storage tank and their respective energy storage capabilities or performance coefficients based on such a non-dimensional analysis. 
Table 3. Rating coefficients for the $1.9 \mathrm{~m}^{3}$ (500 gal) water tank

TEST

DE SCRIPT ION

Charge-2

Discharge-2

Discharge $-2 *$

Charge -4

Discharge-4

Charge-1

Discharge-1

Charge-1/2

Di scharge $-1 / 2$

\section{PERFORMANCE COEFFICIENT}

$\%$

88

84

55

88

84

85

79

86

85

* Cool inlet transfer fluid introduced into top of the water tank. 


\section{Temperature Step Change}

Of all the transient tests performed, four were specifically called for in ASHRAE Standard 94-77. The remaining transient tests performed were at higher flow rates representative of conditions that did exist at one time or another during the operation of the solar heating and cooling system. For all transient tests performed, a $15^{\circ} \mathrm{C}\left(27^{\circ} \mathrm{F}\right)$ temperature step was inftially attempted. As is seen in Table 1 , this temperature step was not consistently obtained. This is attributed to:

1. The process of raising the temperature of the $3.8 \mathrm{~m}^{3}(1000$ gal) water tank and obtaining steady-state conditions was quite tedious (especially at the lowe $\mathrm{r}$ flow rates). As was mentioned earlier, charge and discharge tests were performed in series by raising or lowering the large tank medium at least by twice the amount of the temperature step required. Once elther of the two types of tests was performed, steady-state conditions had to be reestablished in both tanks.

The smaller tank proved to be less of an encumbrance in the establishment of steady-state conditions. However, as Figure 10 shows, the transfer fluid was allowed to reenter the large tank, enabling the mixing process to take place within the closed loop. Since the large tank was twice the volume of the smaller tank, after one test $r$ un was completed, the large tank storage medium was at non-steadystate conditions. Therefore, it was circulated as shown in Figure 12 to reestablish a uniform storage medium temperature once again. This would usually result in a final uniform storage medium temperature only approximately equal to the desired $15^{\circ} \mathrm{C}\left(27^{\circ} \mathrm{F}\right)$ temperature step. This resulting storage medium temperature was accepted and a second test run was performed.

2. There was difficulty in regulating the flow rates. The problem was traced to mechanical backlash within the proportional valves. This resulted in an improper mixing of the storage medium of the larger tank with the test tank mediun.

3. Cold or hot slugs within the loops themselves were credited for some of the initial step change error. Once the exchange was initialized, a considerable length of $3.2 \mathrm{~cm}$ (1-1/4 in) piping had to be flushed before the large tank reservoir fluid reached the small test tank. That fluid flushed was at a temperature different from that of the reservoir fluid. 
The Standard states that the time to reach $90 \%$ of the transfer fluid step change shall not exceed $2 \%$ of the test duration, $\tau_{c, d}$. For the transient response tests performed, this criterion was not met. Table 4 shows the actual times and temperature steps achieved. Reference to the graphical plots of temperature versus time reveals the lag involved in reaching the desired temperature step.

The best results for minimizing the time required to reach the desired step change in temperature resulted in precirculating the transfer fluid in the lines to avoid hot or cold slugs. Once the transfer from the large tank to the small tank was initialized, no attempt was made to obtain a precise $15^{\circ} \mathrm{C}\left(27^{\circ} \mathrm{F}\right)$ temperature step when the transfer did not yield such a step.

Non-Dimensional Analysis

The purpose of the ASHRAE Standard 94-77 test procedure is to provide a standard method for determining the thermal performance of thermal energy storage devices. This procedure was applied to a $1.9 \mathrm{~m}^{3}$ (500 gal) water tank and the "effective" charge and discharge capacities were determined. However, the meaning of such values tends to become blurred when they are utilized in any attempt to compare thermal storage devices. It was for this reason that the non-dimensional analysis was proposed [5].

The utility of such a non-dimensional analysis becomes apparent when one refers to Table 2. This table reveals a variety of "effective" charge and discharge capacities. For example, the 2-hour charge test performed resulted in a $C_{c}$ equal to $9.29 \times 10_{7} \mathrm{~J}$ where the 2-hour discharge test resulted in a $C_{d}^{c}$ equal to $7.63 \times 10^{7} \mathrm{~J}$. The reason for such a discrepency is revealed by referring to Table 1 . This table shows that there existed a $2^{\circ} \mathrm{C}$ difference between the temperature step change achieved per test.

Reference to Table 3 reveals that the charge and discharge tests in the above-cited example display nearly the same performance coefficients $(88 \%$ and $84 \%)$. A further viewing of this table reveals that all the transient tests exhibited nearly the same performance coefficients except the reverse mode Discharge-2 Test (this particular test was performed to deliberately eliminate any possibility of stratification and consequentially the storage capability was much lower). Therefore, it is seen that by utilizing the "effective" charge and discharge capacities obtained via the ASHRAE Standard in a non-dimensional analysis, a meaningful overall rating coefficient can be obtained. It should also be pointed out that since the dimensionless time used in the abscissa of the non-dimensional plots includes the transfer fluid specific heat, the performance coefficient should also be independent of the transfer fluid. Since only one fluid was used in this study, this could be not verified. 


\section{Table 4. Times for the achievement of the step- change in entering transfer fluid \\ temperature during the transient tests.}

\begin{tabular}{|c|c|c|c|c|c|}
\hline $\begin{array}{c}\text { TEST } \\
\text { DESCRIPTION }\end{array}$ & ${ }^{\circ} \mathrm{C}$ & $\begin{array}{c}(.90) \\
{ }^{\circ} \mathrm{C}\end{array}$ & ${ }_{m}^{\tau} \mathcal{I}_{n} d$ & $\underset{\min }{(.02) \tau} c, d$ & $\begin{array}{l}\text { Actual Time } \\
\text { Utilized } \\
\text { min }\end{array}$ \\
\hline Charge-2 & 15.3 & 13.8 & 120 & 2.4 & 3.6 \\
\hline Discharge -2 & 13.4 & 12.1 & 120 & 2.4 & 4.8 \\
\hline Di scharge -2 * & 14.7 & 13.2 & 120 & 2.4 & 4.5 \\
\hline Charge -4 & 15.4 & 13.9 & 240 & 4.8 & $7.0 * *$ \\
\hline Di scharge-4 & 14.4 & 12.9 & 240 & 4.8 & 3.6 \\
\hline Charge-1 & 15.3 & 13.8 & 60 & 1.2 & 1.8 \\
\hline Di scharge-1 & 16.8 & 15.1 & 60 & 1.2 & $6.0 * *$ \\
\hline Charge $-1 / 2$ & 13.8 & 12.4 & 33 & 0.7 & 2.2 \\
\hline Di scharge $-1 / 2$ & 12.6 & 11.3 & 33 & 0.7 & 1.4 \\
\hline
\end{tabular}

* Cool inlet transfer fluid introduced into top of the water tank. ** Unexplained cold or hot slug present at test initiation. 
Upon completing the tests and analysis of data described above, it was decided to reanalyze the results obtained in accordance with a recent paper dealing with the stratification of hot water tanks [13]. In this paper, geometric and dynamic parameter effects on thermal stratification were studied. This study involved plexiglass cylindrical test models, $10.4 \mathrm{~cm}(4.1 \mathrm{in})$ and $24.2 \mathrm{~cm}(9.54 \mathrm{in})$ in diameter, utilizing water as the transfer fluid. The geometric configuration of these models (inlet and outlet port locations, proportions, etc.) were similar to the 1.9 $\mathrm{m}^{3}$ (500 gal) storage tank used in the present study.

The test procedure utilized in [13] was identical to the discharge tests described in this paper. That is, the cold transfer fluid (water) was introduced into the bottom of the model tanks and the hot fluid removed from the top elevation. Determination of the inlet and outlet transfer fluid temperatures during the tests was performed using conventional instrumentation.

A unique concept of extraction efficiency, $n$, was introduced in [13]. It is defined as:

$$
n=\left(\hat{v} t^{*}\right) / V
$$

where,

$$
\begin{aligned}
& \dot{v}=\text { volume flow rate, } \mathrm{m}^{3} / \mathrm{s}(\mathrm{gal} / \mathrm{min}) \\
& t^{*}=\text { time elapsed until } \frac{t_{f, e}-t_{i}}{t_{f, i}-t_{i}}=0.90, s \\
& v=\text { volume of tank, } \mathrm{m}^{3} \text { (gal). }
\end{aligned}
$$

Several factors thought to influence the extraction efficiency were studied in reference [13]. Those of major concern included the inlet port location, inlet geometry, mass flow rate, tank length to diameter ratio, and temperature variation of inlet and outlet transfer fluid. The individual effects of these factors on the extraction efficlency were presented in the paper. Then the effects of all factors were incorporated into one correlation curve. This was accomplished by utilizing three dimensionless groups; Reynolds number, $\mathrm{Re}_{\mathrm{d}}$, (based on the portal diameter), Grashof number, $\mathrm{Gr}_{\mathrm{D}}$, (based on the tank diameter), and the ratio L/D. Figure 17 is the correlation of extraction efficiency taken from [13] with actual data taken in the NBS tests.

The cluster of data points to the left on Figure 17 represent those tests performed on the models and shown in [13]. A least-squares fit of all data taken in both tanks ( 96 cases) yielded this correlation. The curve is mathematically represented as: 


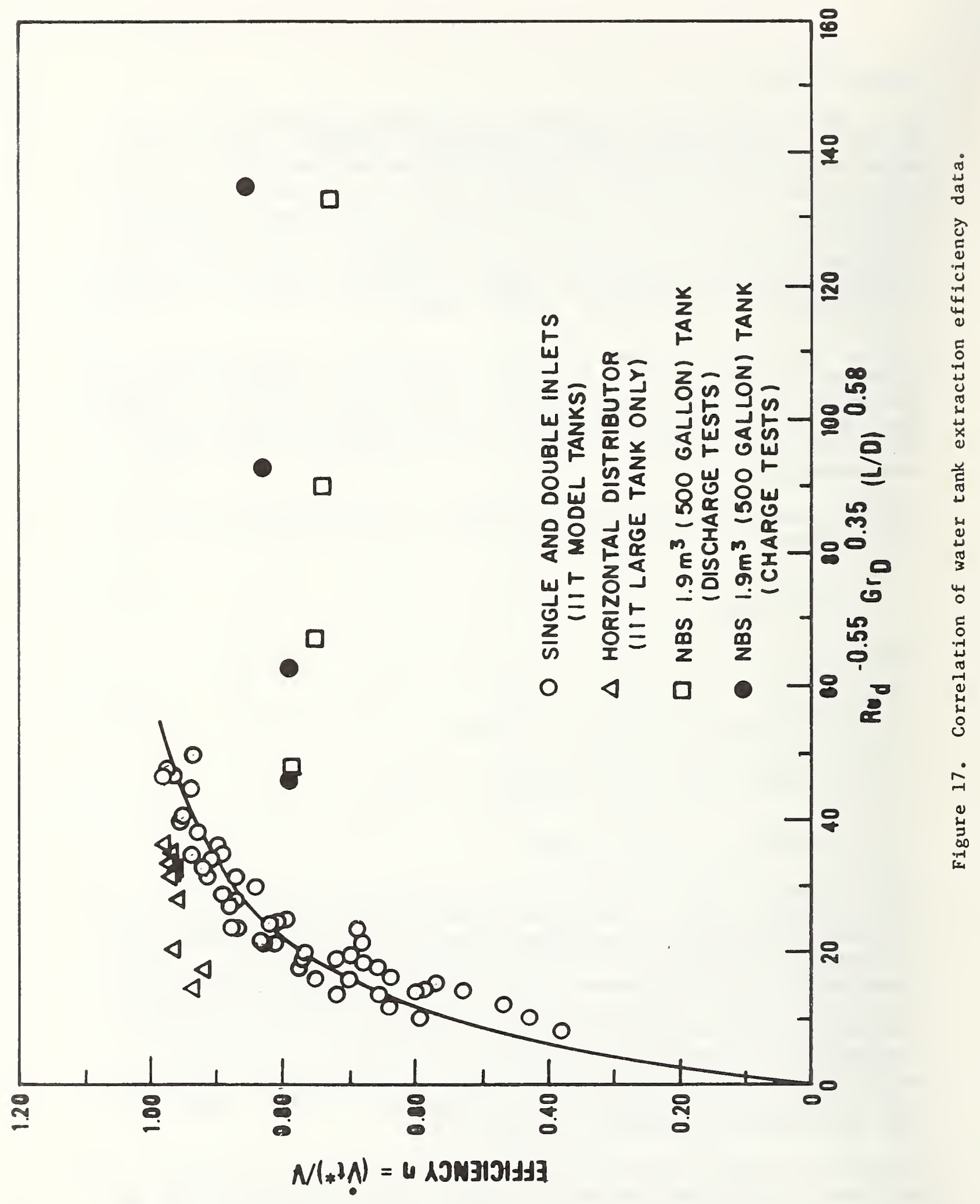




$$
n=1-\left[\exp -0.067 \operatorname{Re}_{\mathrm{d}}^{-0.55} \mathrm{Gr}_{\mathrm{D}}^{0.35}(\mathrm{~L} / \mathrm{D})^{0.58}\right]
$$

The data obtained from the transient charge and discharge test performed in the present study were reanalyzed in accordance with the procedure presented in reference [13]. The correlation of extraction efficiency for each test ( 8 cases) is plotted in Figure 17 for comparison. The tank efficiencies range in the present study from 75 to 85 percent.

The results of the NBS tests show a pronounced spread along the abscissa relative to the test model results of [13]. By individually analyzing the three dimensionless terms comprising the abscissa, the following determinations were made:

1. The Reynolds number is defined as:

$$
\operatorname{Red}=\frac{4 \dot{V}}{\pi v d}
$$

where,

$\mathrm{d}=$ tank inlet diameter, $\mathrm{m}(\mathrm{ft})$

$v=k i n e m a t i c$ viscosity, $\mathrm{m}^{2} / \mathrm{s}\left(\mathrm{ft} \mathrm{t}^{2} / \mathrm{s}\right)$

For the NBS tests, higher volume flow rates were used. However, the inlet diameter and fluid viscosity were also larger resulting in approximately the same Reynolds number values for the present tests and those reported in [13].

2. The ratio of tank length to tank diameter, L/D, utilized for the test models was similar to the values used in the present study.

3. The Grashof number is defined as:

$$
G r_{D}=\left[\rho^{2} g B(\Delta t) D^{3}\right] / \mu
$$

where,

$$
\begin{aligned}
& \rho=\text { transfer fluid density, } \mathrm{kg} / \mathrm{m}^{3}\left(1 \mathrm{~b} / \mathrm{ft}^{3}\right) \\
& g=\text { gravitational force, } \mathrm{m} / \mathrm{s}^{2}\left(\mathrm{ft} / \mathrm{s}^{2}\right) \\
& B=\text { coefficient of thermal expansion } 1 /{ }^{\circ} \mathrm{C}\left(1 /{ }^{\circ} \mathrm{F}\right) \\
& \mu=\text { absolute viscosity, } \mathrm{kg} /\left(\mathrm{m}^{\circ} \mathrm{s}\right)(1 \mathrm{~b} /(\mathrm{s} \cdot \mathrm{ft})) .
\end{aligned}
$$

All values comprising the Grashof number are similar in quantity for both the test models and the NBS tank except the tank diameter, D. The test model values were on the order of $0.24 \mathrm{~m}(0.80 \mathrm{ft})$ and $0.10 \mathrm{~m}(0.34 \mathrm{ft})$ in contrast to the $0.91 \mathrm{~m}$ ( $3 \mathrm{ft}$ ) value of the NBS tank used in this study. 
It is noted that this value is cubed in the numerator of the Grashof number.

The much larger tank and hence much larger Grashof number is considered to be the major reason for the discrepancy between the correlation of [13] and the data of the present study as indicated in Figure 17. However, Lavan and Thompson do point out in reference [13] that deviations from their correlation should be expected for commercially avallable tanks made of steel. As noted, steel has a thermal conductivity two orders of magnitude larger than plexiglass and the increased conductive heat flow through the walls could be expected to adversely affect the stratification and thus the efficiency.

Table 5 compares the mass flow rates per cross sectional area utilized for the NBS tests and the model tests of [13]. Due to the large diameter of the tank tested in this study, the flow rates were insufficient to generate values as large as those listed in the table for the test models. 


\section{Table 5. Mass flow rate per tank cross sectional area for the $1.9 \mathrm{~m}^{3}$ (500 gal) test tank and the test models of [13].}

Tank Diameter, D,

NBS

$0.91 \mathrm{~m} \quad(3 \mathrm{ft})$

$1.70(145)$

$3.42(291)$

$6.96(593)$

$12.54(1068)$
IIT*

$0.24 \mathrm{~m}(0.80 \mathrm{ft})$

$0.70(60)$

$1.88(160)$

$14.67(1250)$

$17.61(1500)$
IIT*

$0.10 \mathrm{~m}(0.34 \mathrm{ft})$

$3.52(300)$

$9.39(800)$

$73.39(6250)$

$88.07(7500)$

All units, $\mathrm{kg} /\left(\mathrm{m}^{2} \cdot \mathrm{s}\right) \times 10^{-3}\left(1 \mathrm{~b} /\left(\mathrm{ft} \mathrm{t}^{2} \cdot \mathrm{h}\right)\right)$

* Illinois Institute of Technology model water tank studies [13]. 


\section{CONCLUSIONS AND RECOMMENDATIONS}

A total of nine tests structured after ASHRAE Standard 94-77 we re used to test a $1.9 \mathrm{~m}^{3}$ (500 gal) water tank thermal storage device. A description of these tests, the data reduction procedure, and the test results have been presented in this paper. It was found that the heat loss characteristics and the amount of energy charged into or discharged from the device could be quantified through the utilization of the Standard. However, based on this study, the following recommendations are made:

1. Leniency should be allowed with respect to the specified test requirements for a $15^{\circ} \mathrm{C}\left(27^{\circ} \mathrm{F}\right)$ temperature step change. It was shown that adequate results were obtained without $a$. precise $15^{\circ} \mathrm{C}$ step provided the results were presented in non-dimensionless terms.

2. The dimensionless plots described in this paper should be used in the analysis of the results. The utilization of such plots should provide a substantial means for comparing the thermal performance of different storage devices.

3. An incorporation of the stagnant heat loss test as performed in this study should be allowed as an alternate technique in the Standard. 


\section{REFERENCES}

1. Hill, J.E., and T. Kusuda, "Method of Testing for Rating Solar Collectors Based on Thermal Performance," NBS Report NBSIR 74-635, December, 1974.

2. Kelly, G.E., and J.E. Hill, "Method of Testing for Rating Thermal Storage Devices Based on Thermal Performance," NBS Report NBSIR 74-634, April, 1975.

3. Hill, J.E., Streed, E.R., Kelly, G.E., Geist, J.C., and T. Kusuda, "Development of Proposed Standards for Testing Solar Collectors and Thermal Storage Devices," NBS Technical Note 899, February, 1976.

4. Hill, J.E., and E.R. Streed, "A Method of Testing for Rating Solar Collectors Based on Thermal Performance," Solar Energy, Vol. 18, pp. 421-429, 1976.

5. Hill, J.E., Kelly, G.E., and B.A. Peavy, "A Method of Testing for Rating Thermal Storage Devices Based on Thermal Performance," Solar Energy, Vol.19, pp. 721-732, 1977.

6. ASHRAE Standard 94-77, "Methods of Testing Thermal Storage Devices Based on Thermal Performance," ASHRAE, 345 E. 47 th St., N.Y., N.Y. $10017,1977$.

7. ASHRAE Standard 93-77, "Methods of Testing to Determine the Thermal Performance of Solar Collectors," ASHRAE, 345 E. 47 th St. N.Y., N.Y. $10017,1977$.

8. Hill, J.E., Jenkins, J.P., and D.E. Jones, "Testing of Solar Collectors According to ASHRAE Standard 93-77," ASHRAE Transactions, Vol. 84, Part II, 1978.

9. Peavy, B.A., Burch, D.M., Powe11, F.J., and C.M. Hunt, "Comparison of Measured and Computer-Predicted Thermal Performance of a Four Bedroom Wood-Frame Townhouse," NBS Building Science Series 57, Apri1, 1975.

10. Burch, D.M., Peavy, B.A., and F.J. Powe11, "Comparison between Measured and Computer-Predicted Hourly Heating and Cooling Energy Requirements for an Instrumented Wood Framed Townhouse," ASHRAE Transactions, Vol. 81, Part II, 1975.

11. Hil1, J.E., and T.E. Richtmyer, "Retrofitting a Residence for Solar Heating and Cooling - The Design and Construction of the System," NBS Technical Note 892, November, 1975. 
12. ASHRAE Handbook of Fundamentals, ASHRAE, 345 E. 47th St., N.Y., N.Y. 10017, Pp. 275-284, 1972 .

13. Lavin, Z., and J. Thompson, "Experimental Study of Thermally Stratified Hot Water Tanks," Solar Energy, Vol. 19, pp. 519-524, 1977. 
9. APPENDIX A

Time-Temperature Relationships for the Transfer Fluid during the Transient Storage Tests 


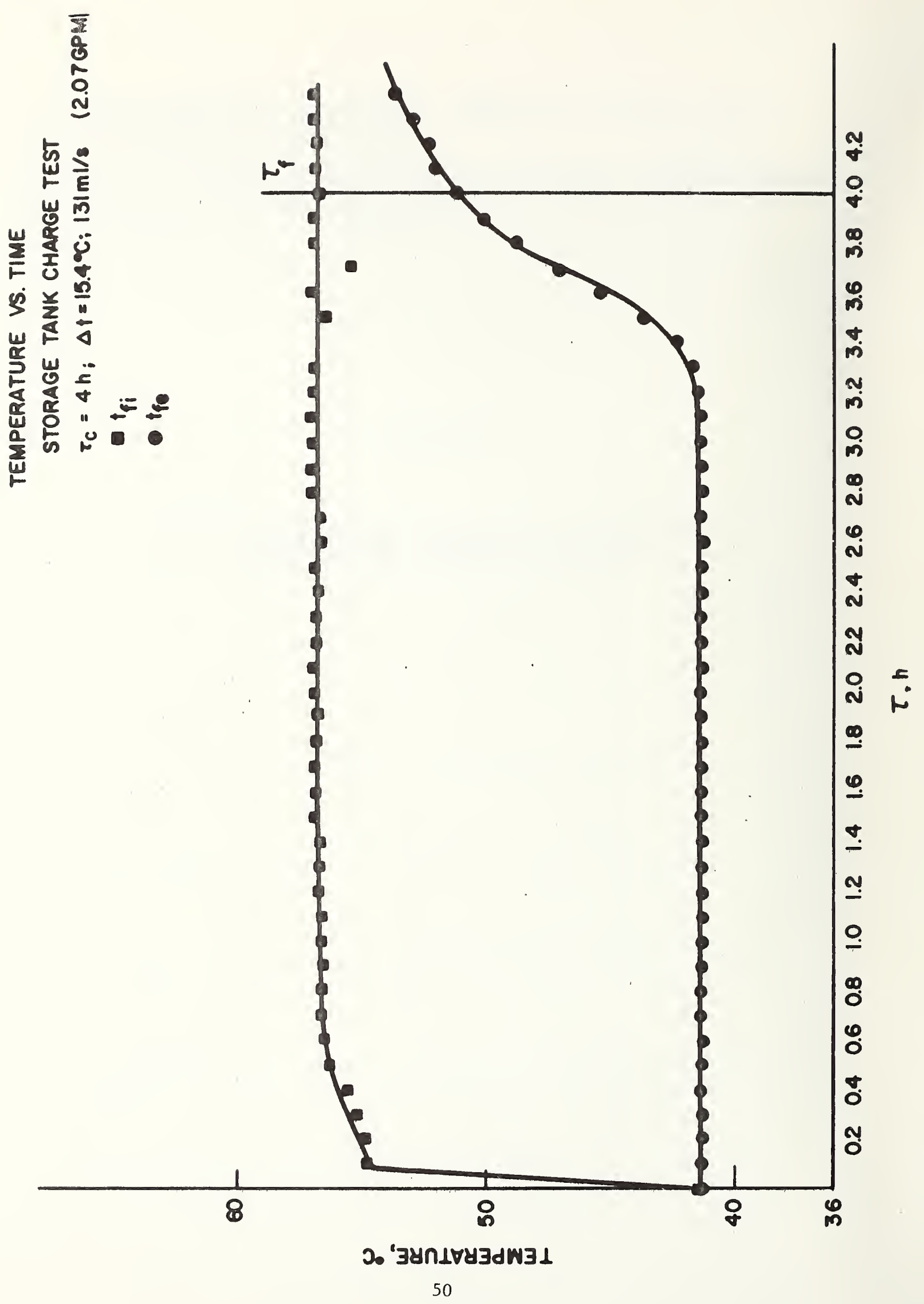




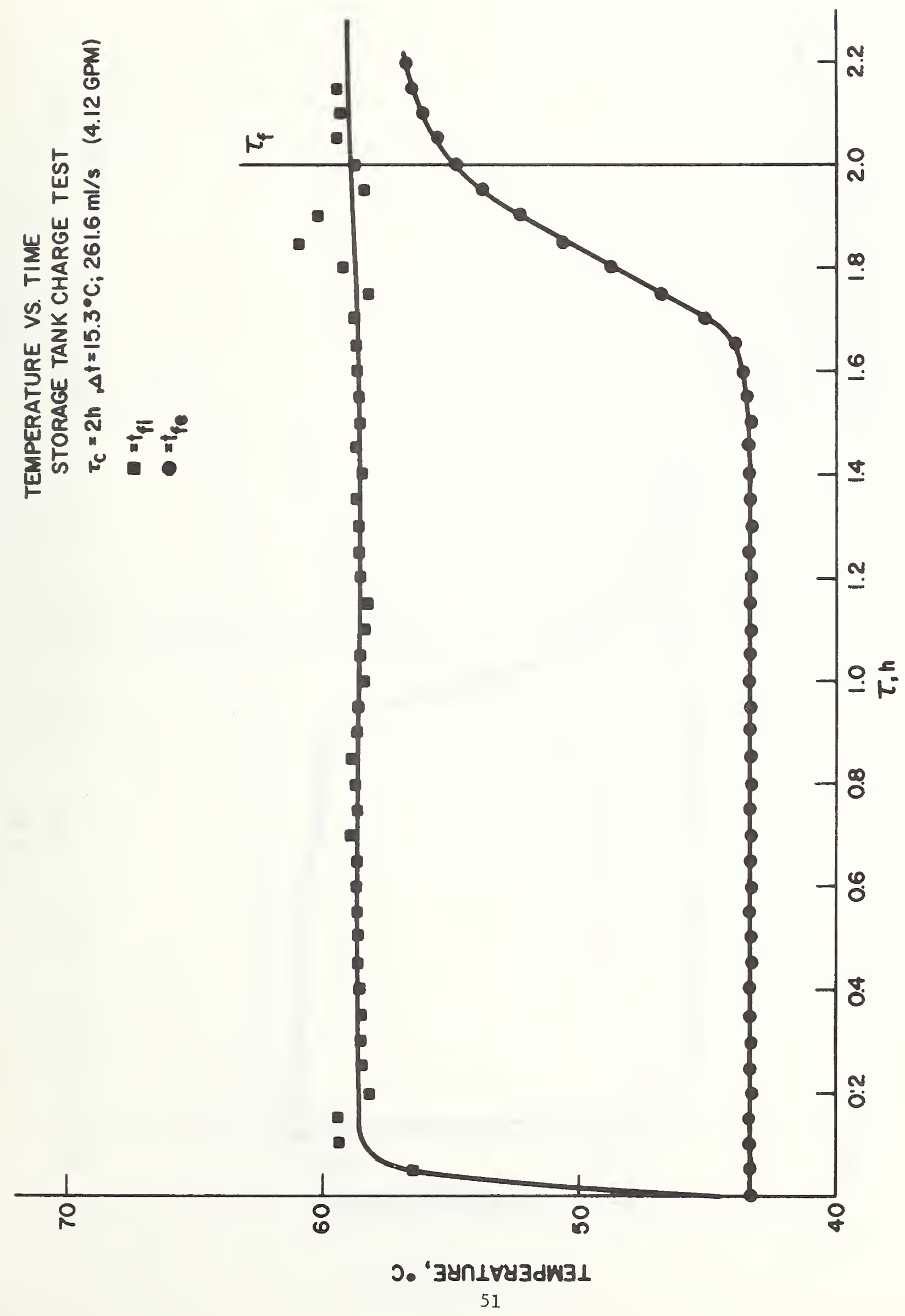




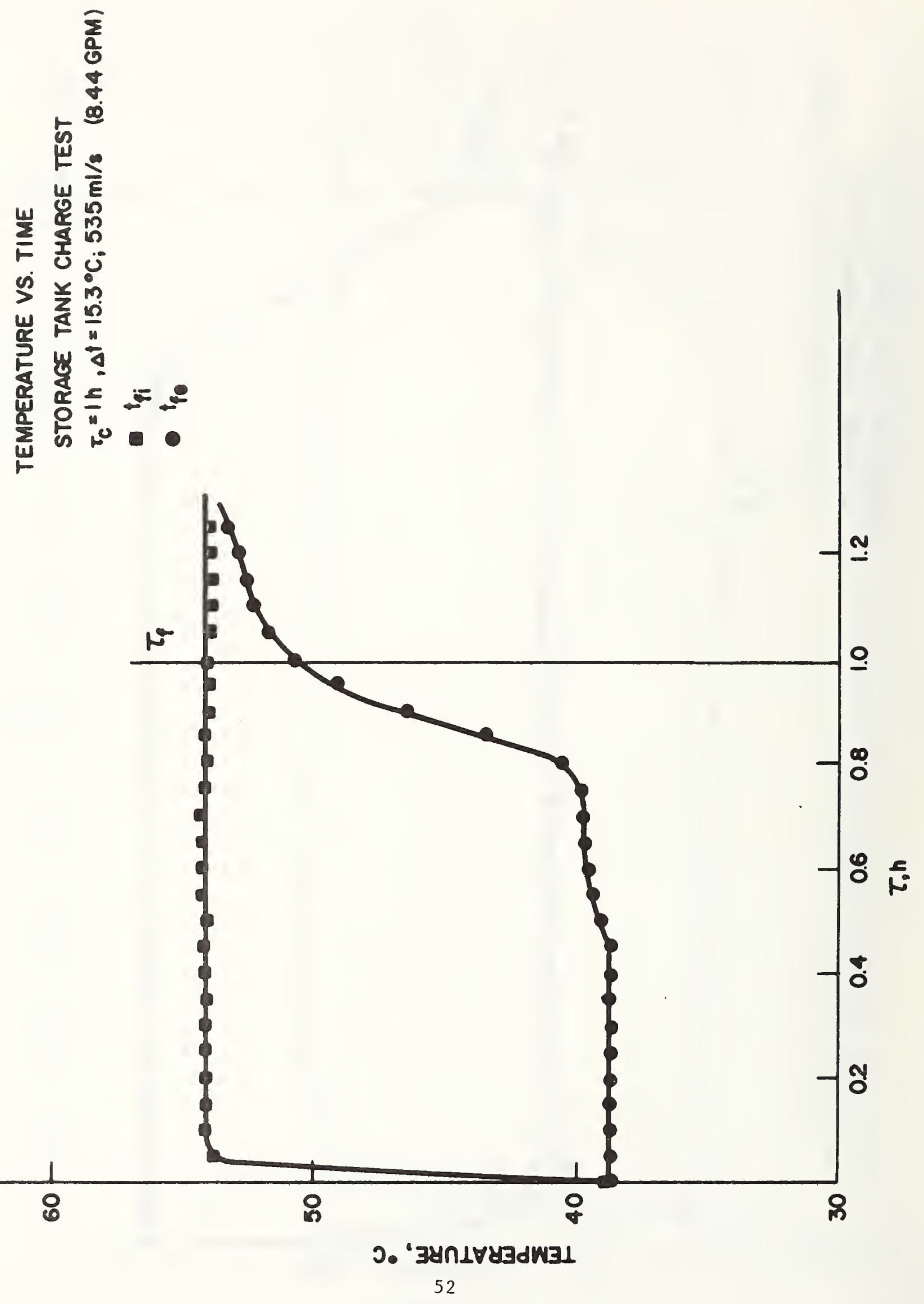




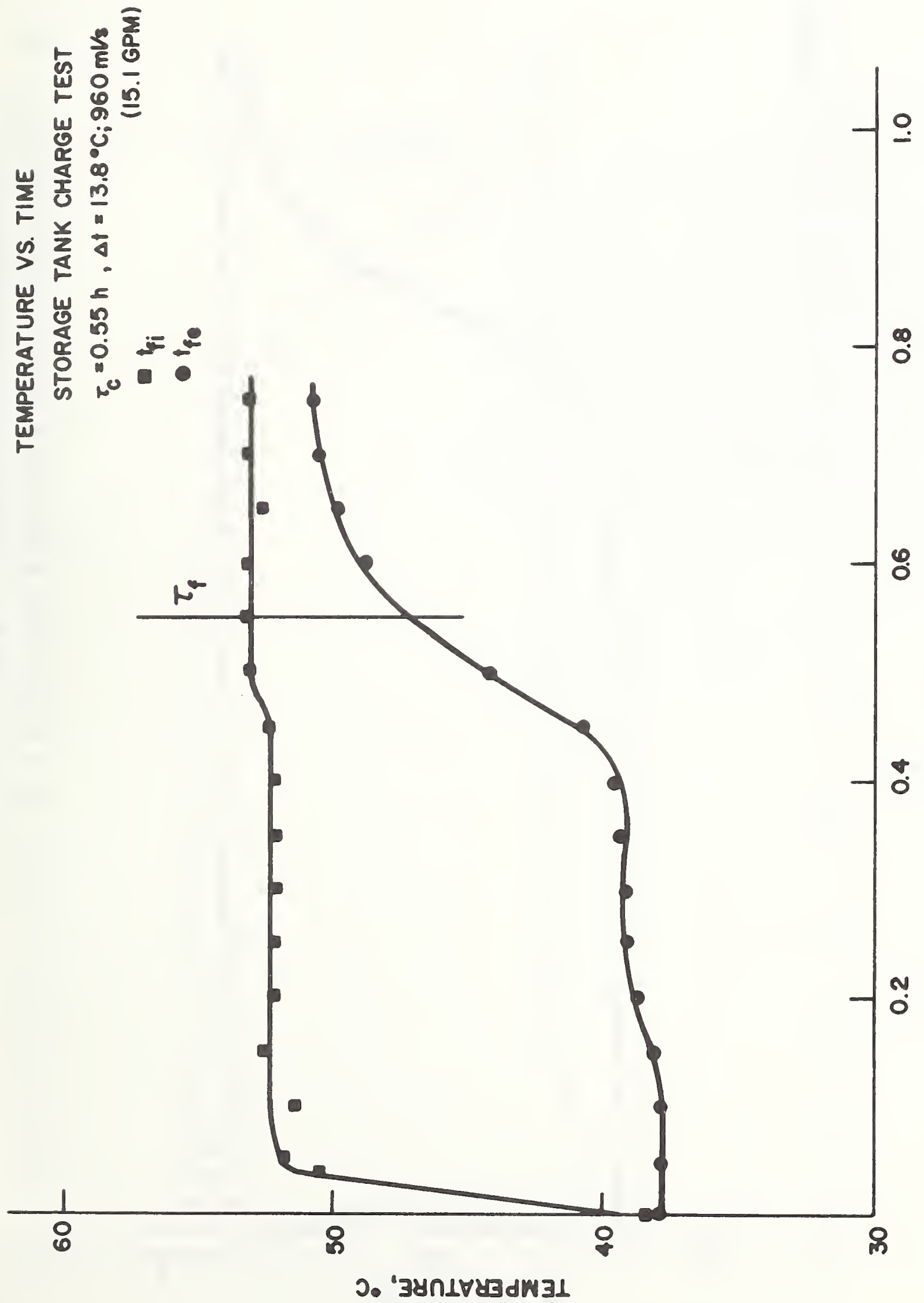




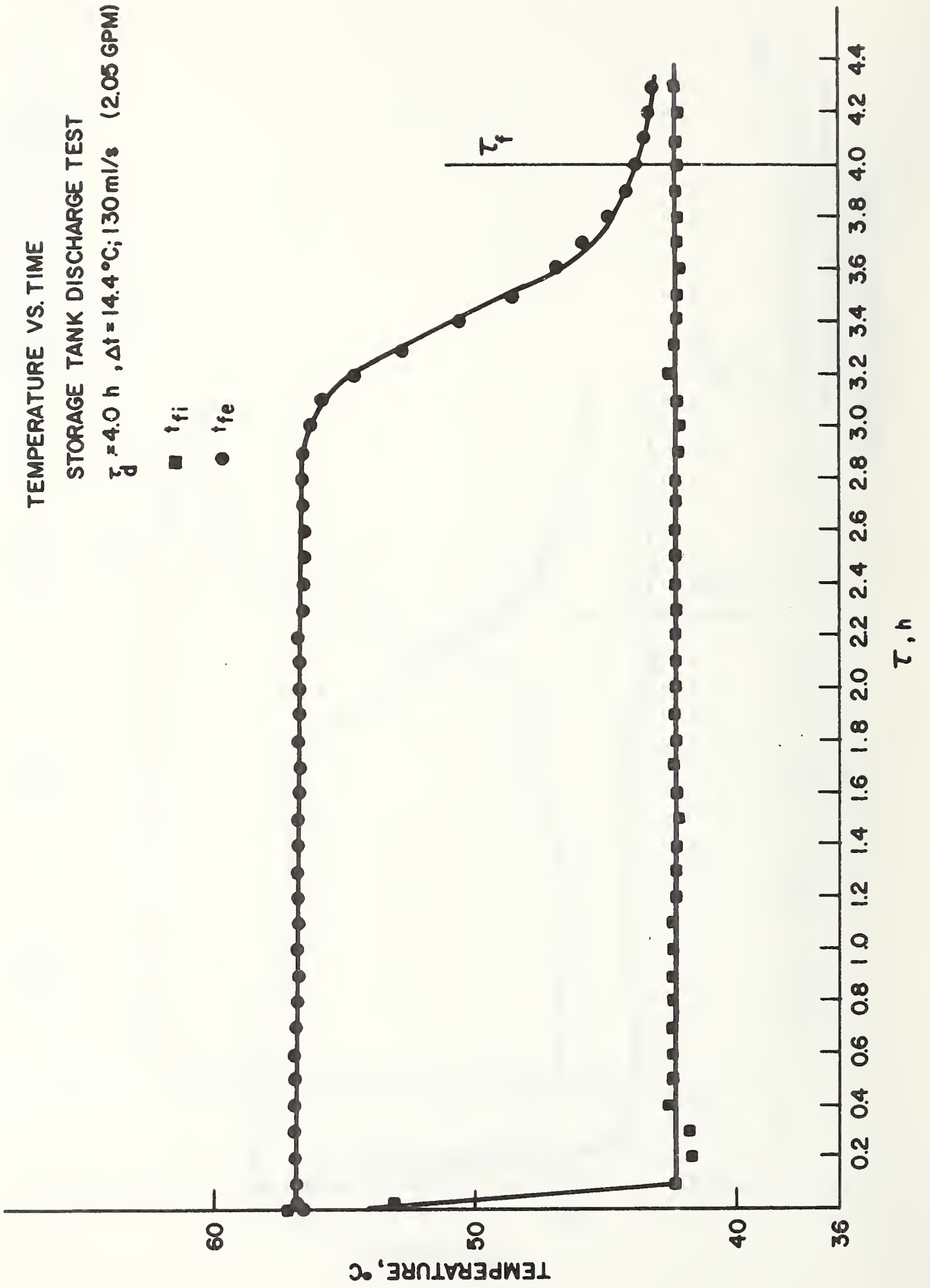




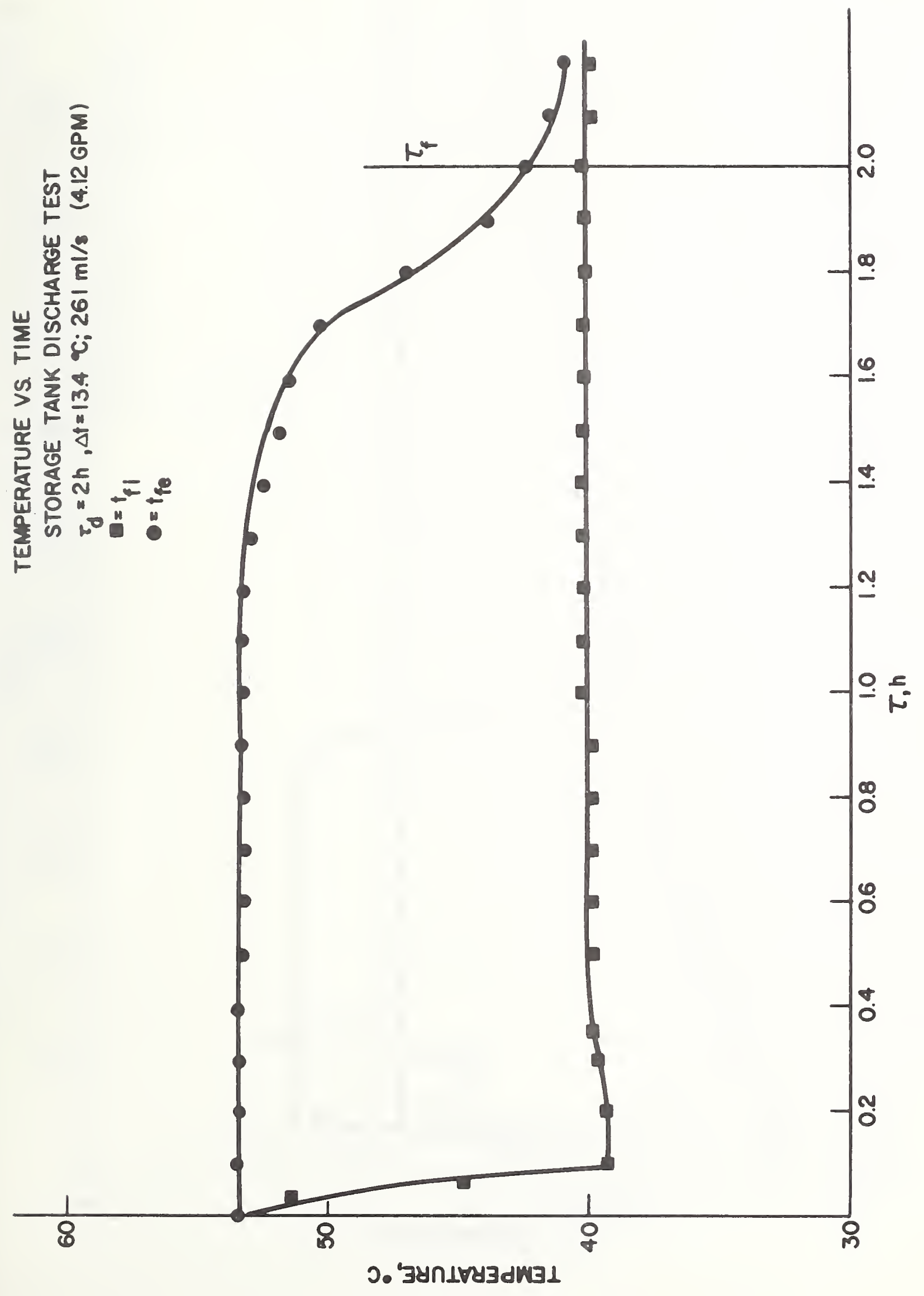




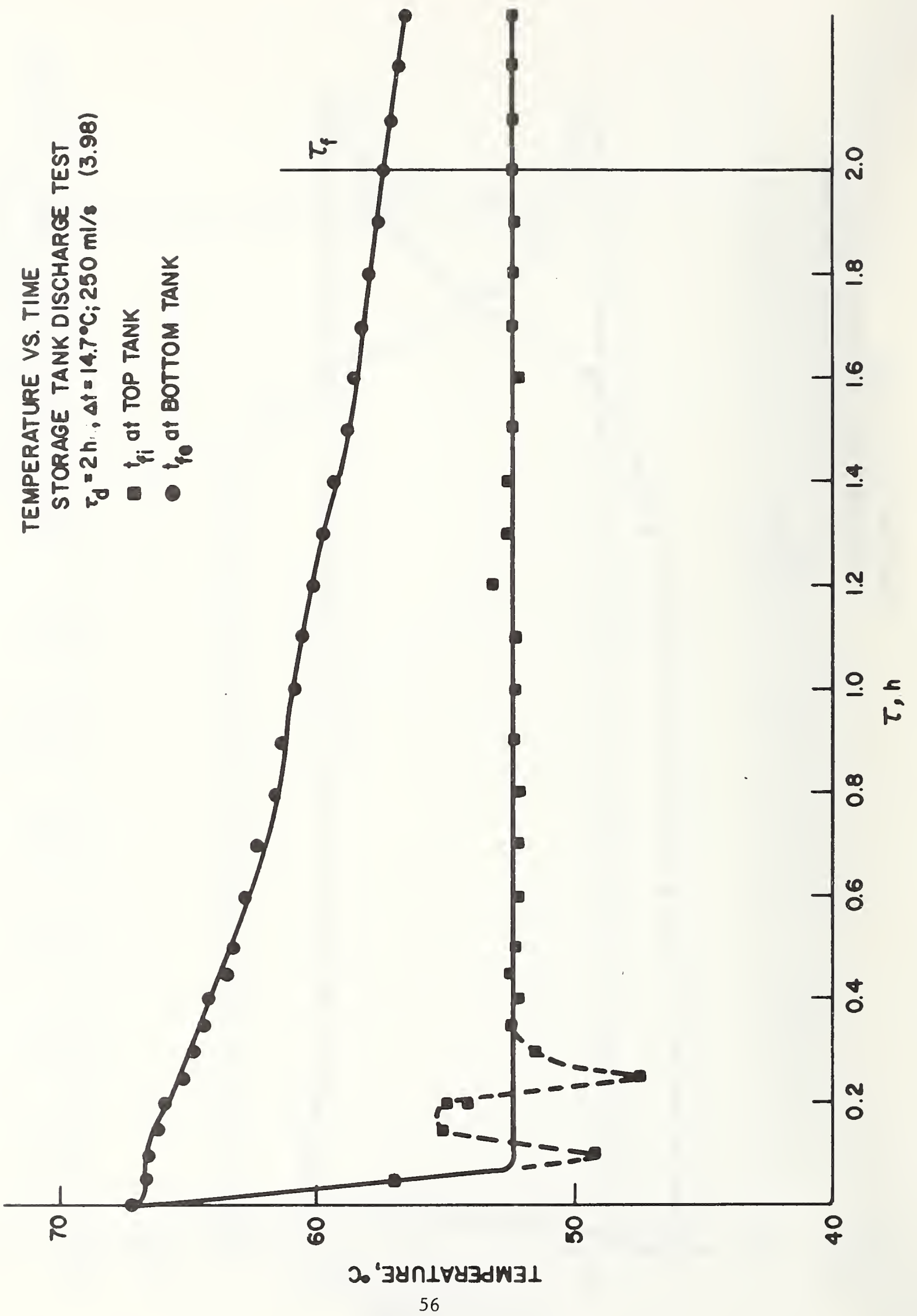



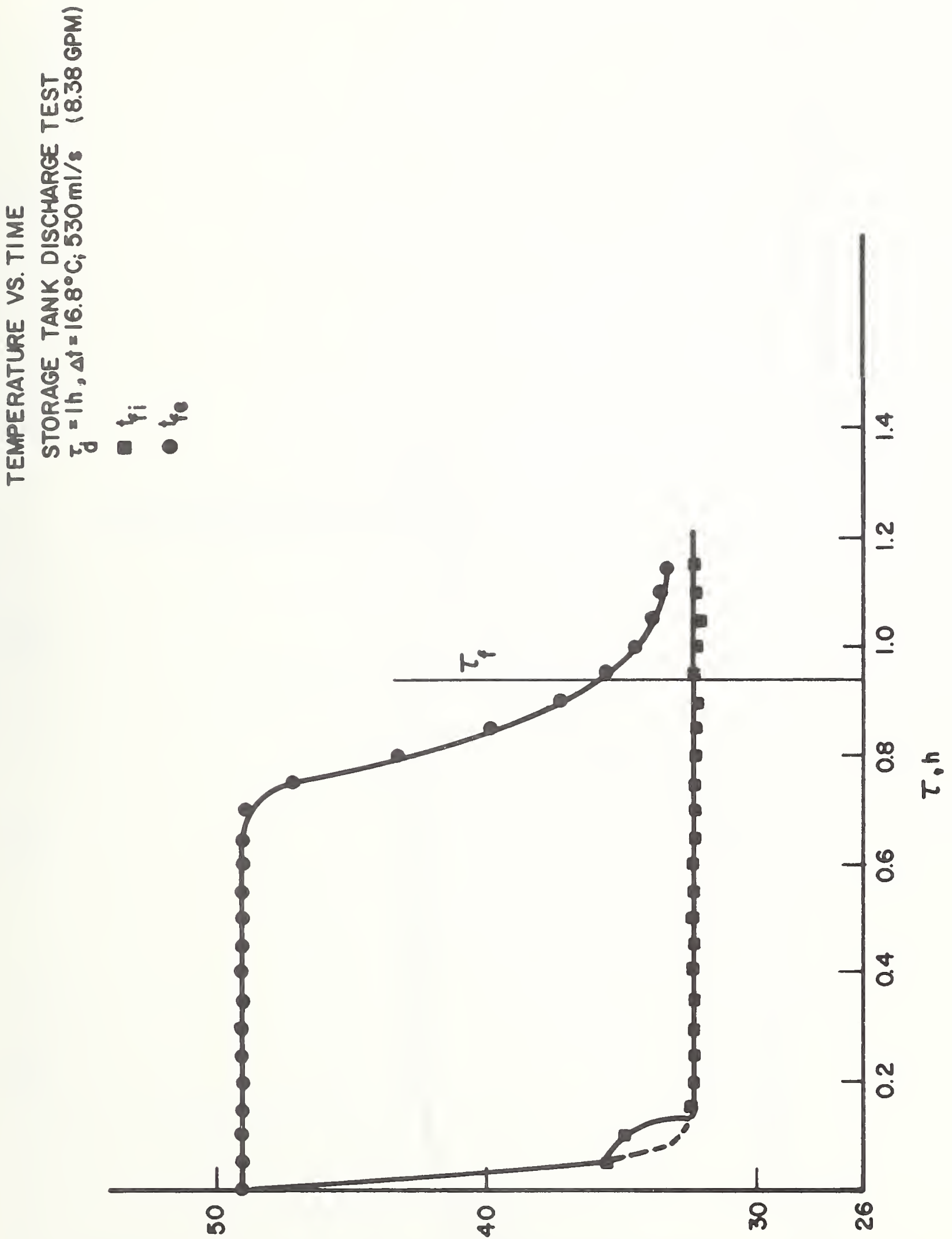

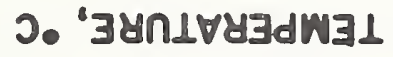




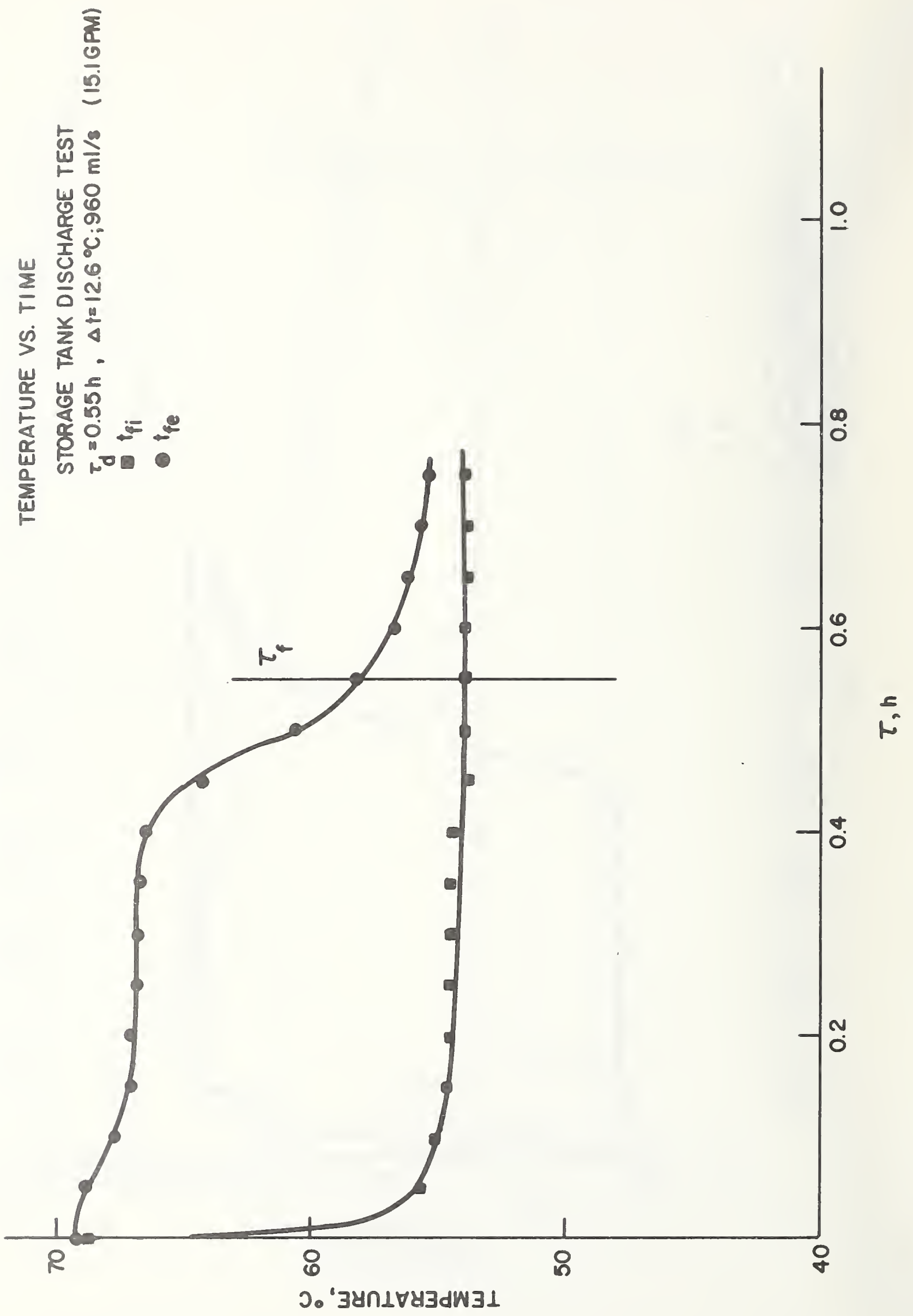


10. APPENDIX B

Dimensionless Time-Temperature Relationships for the Transfer Fluid during the Transient Storage Tests 


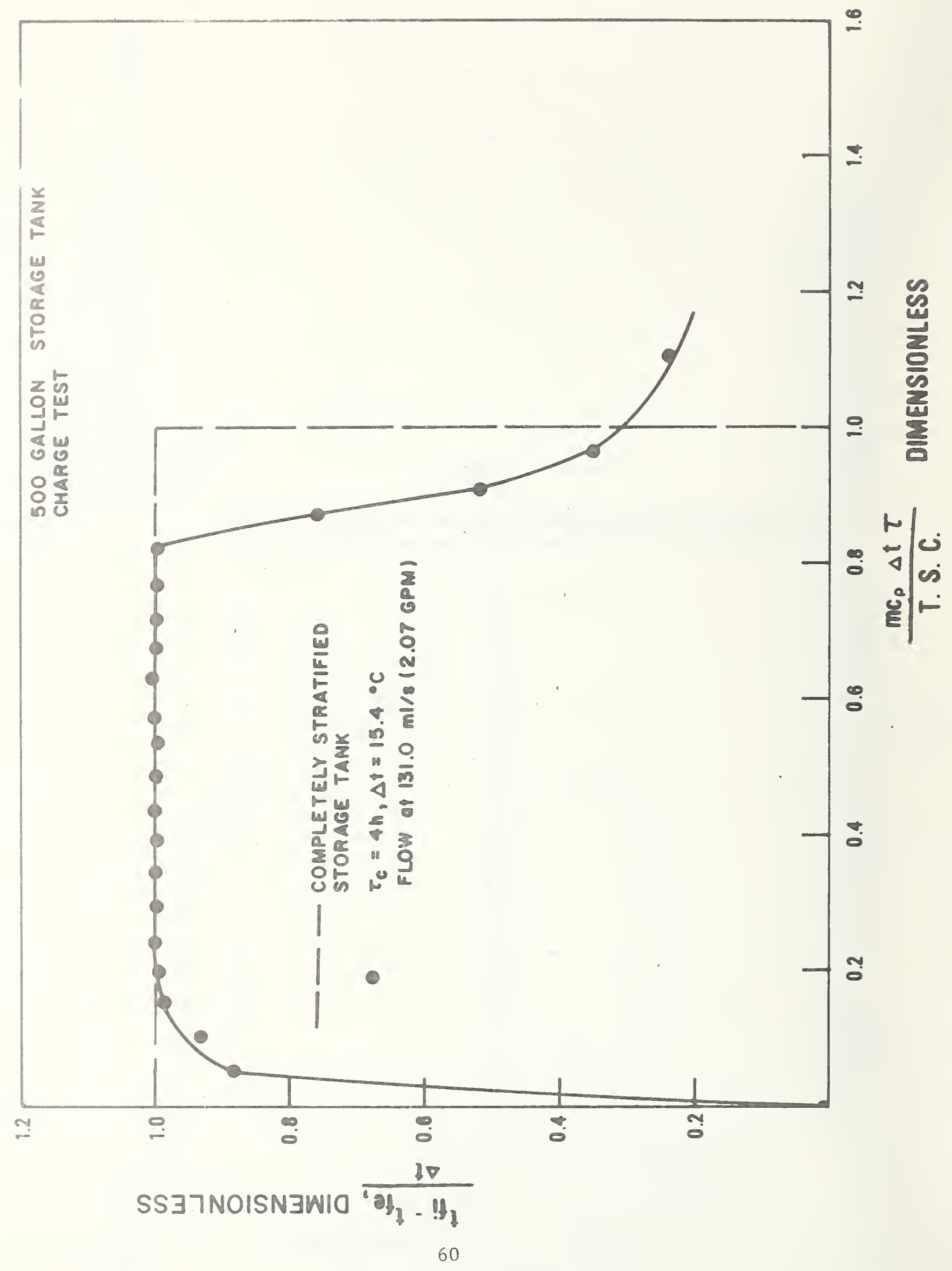




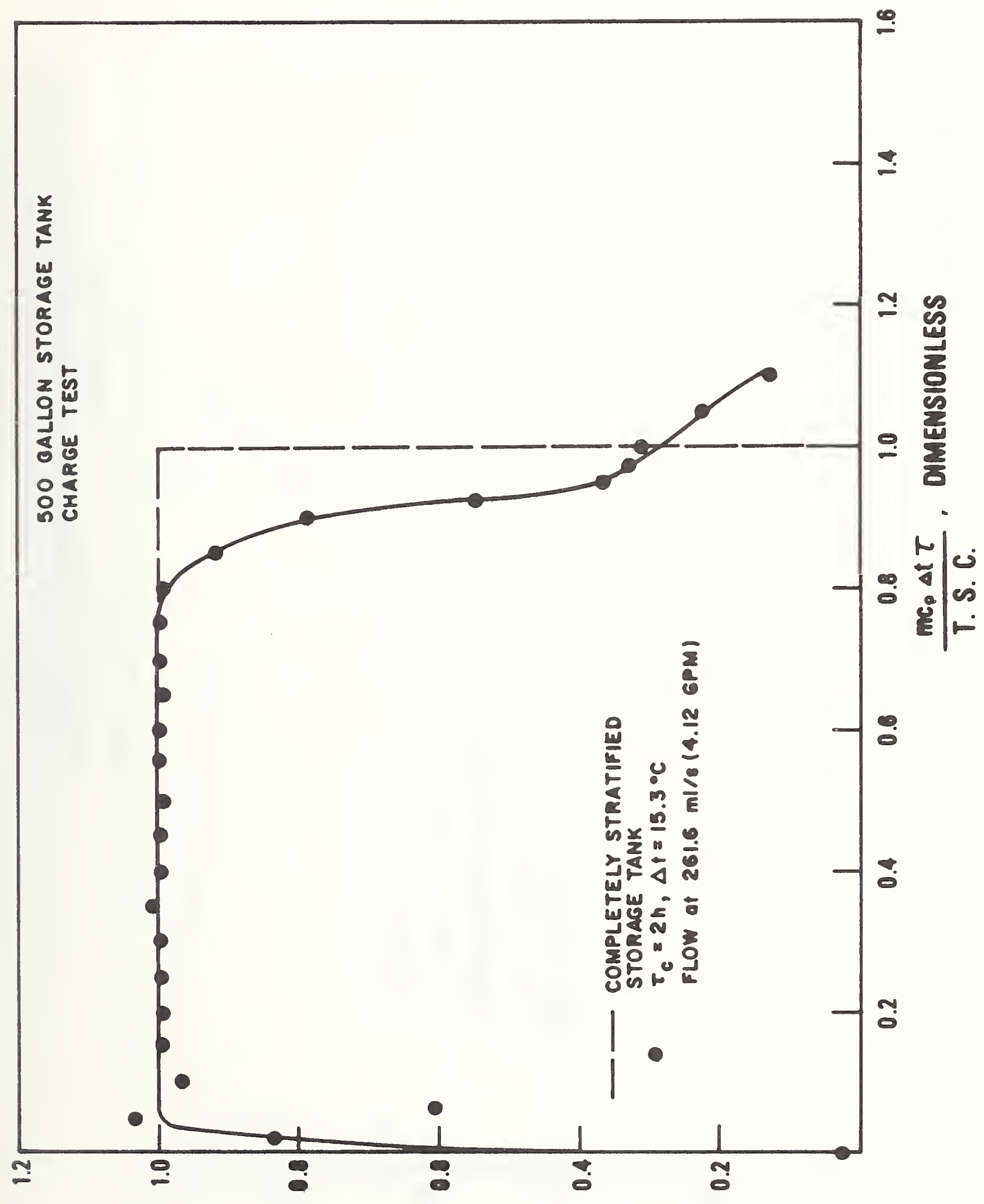

SS3าMOISN3mid $\cdot \frac{10}{4 !-44}$ 


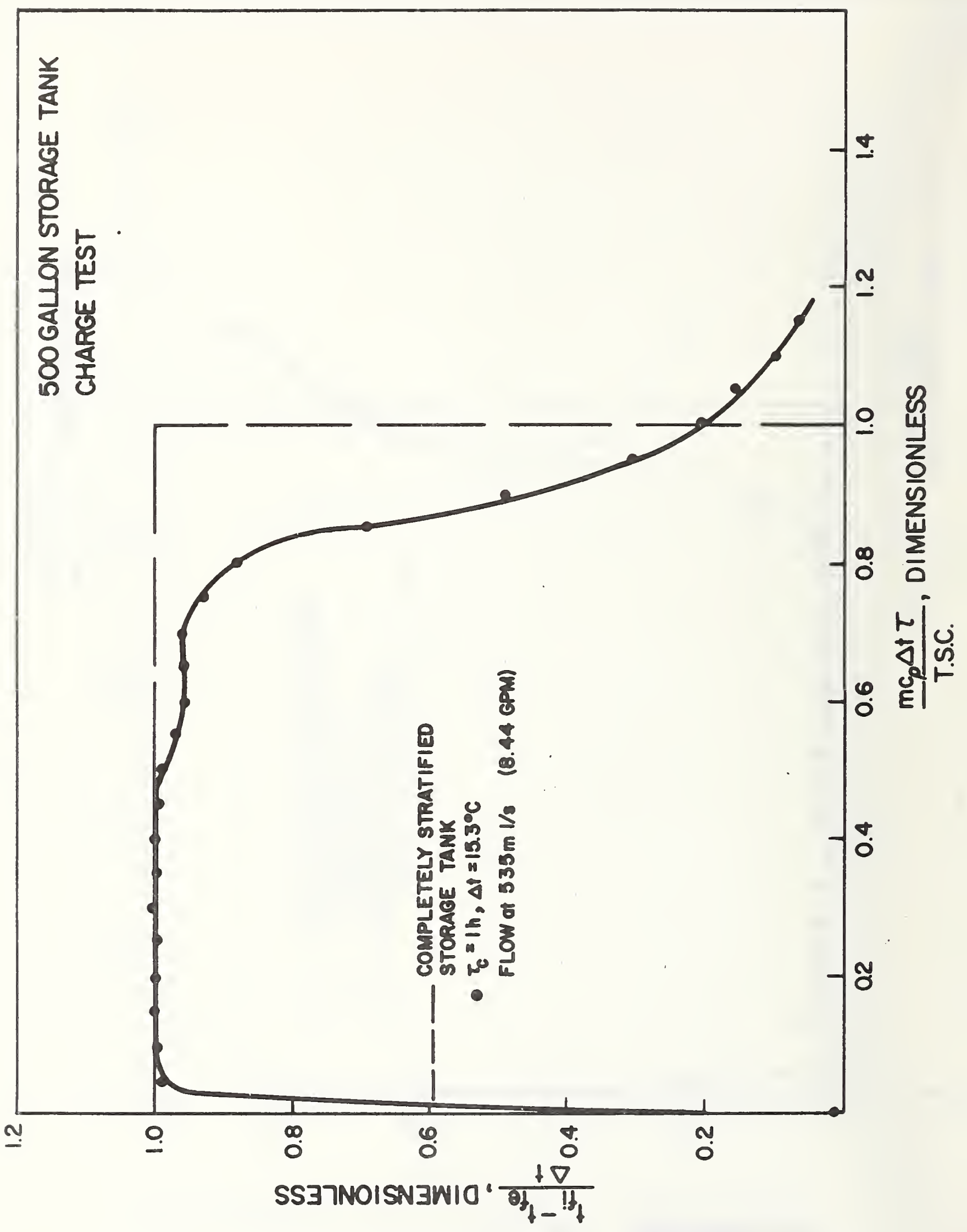




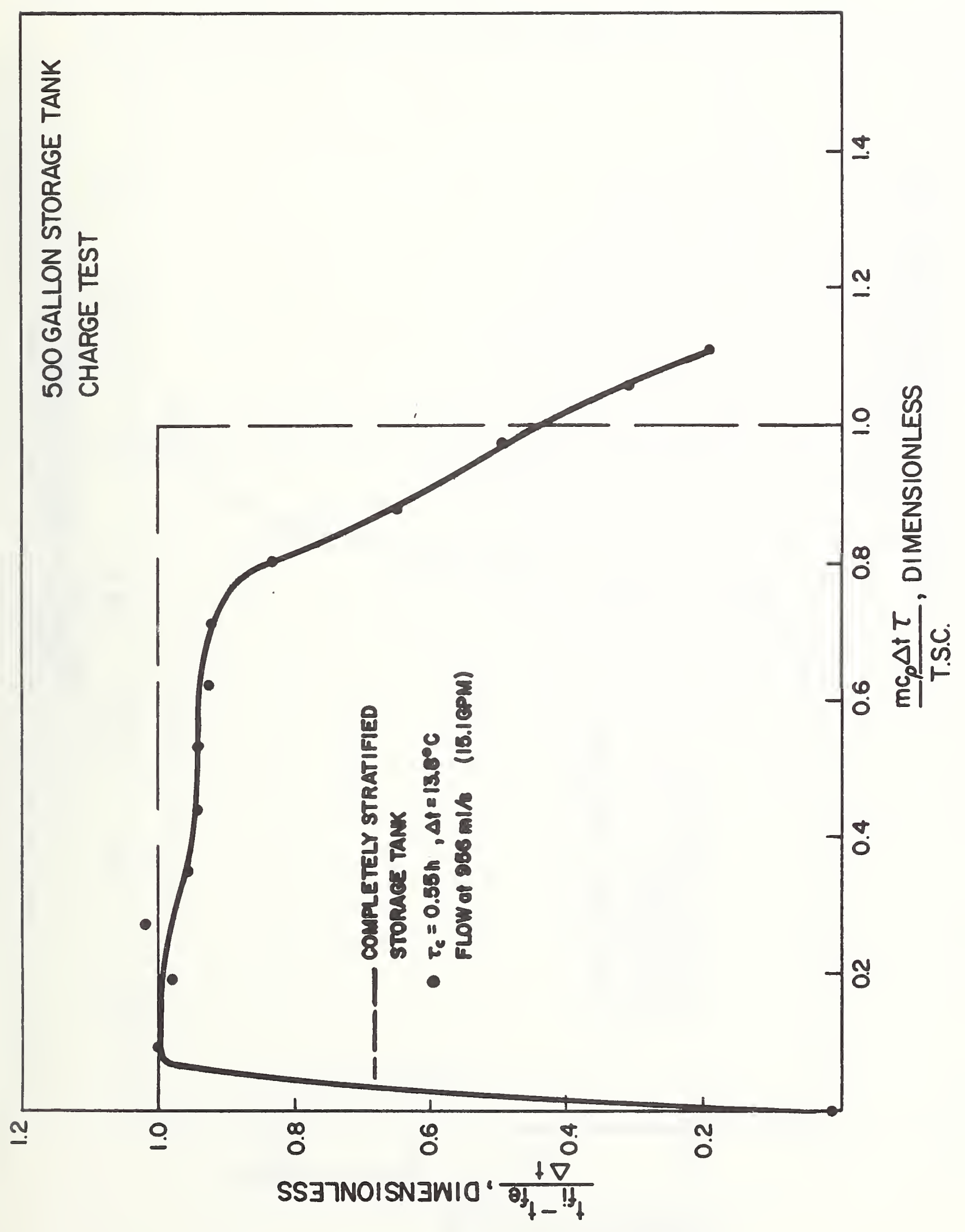




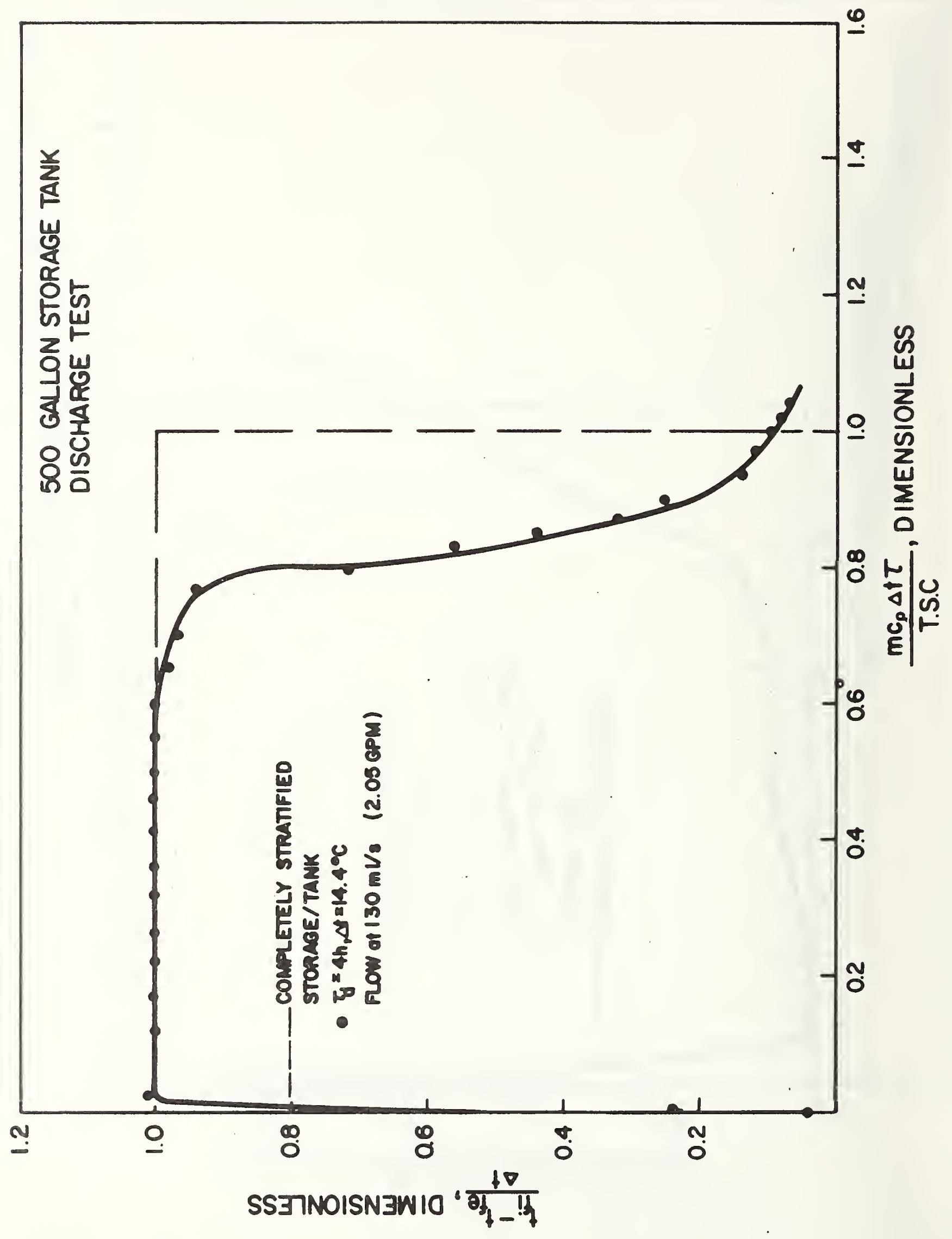




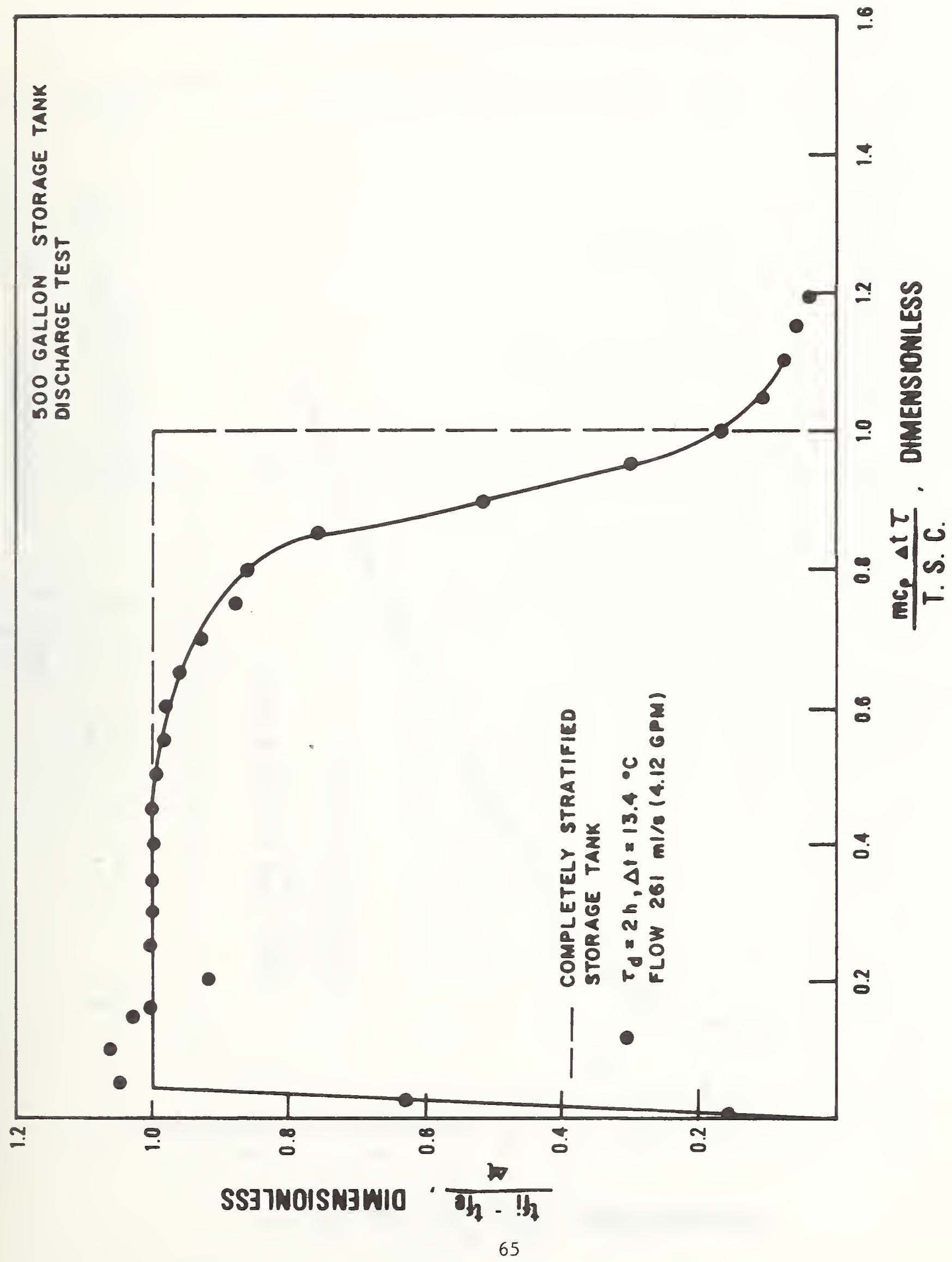




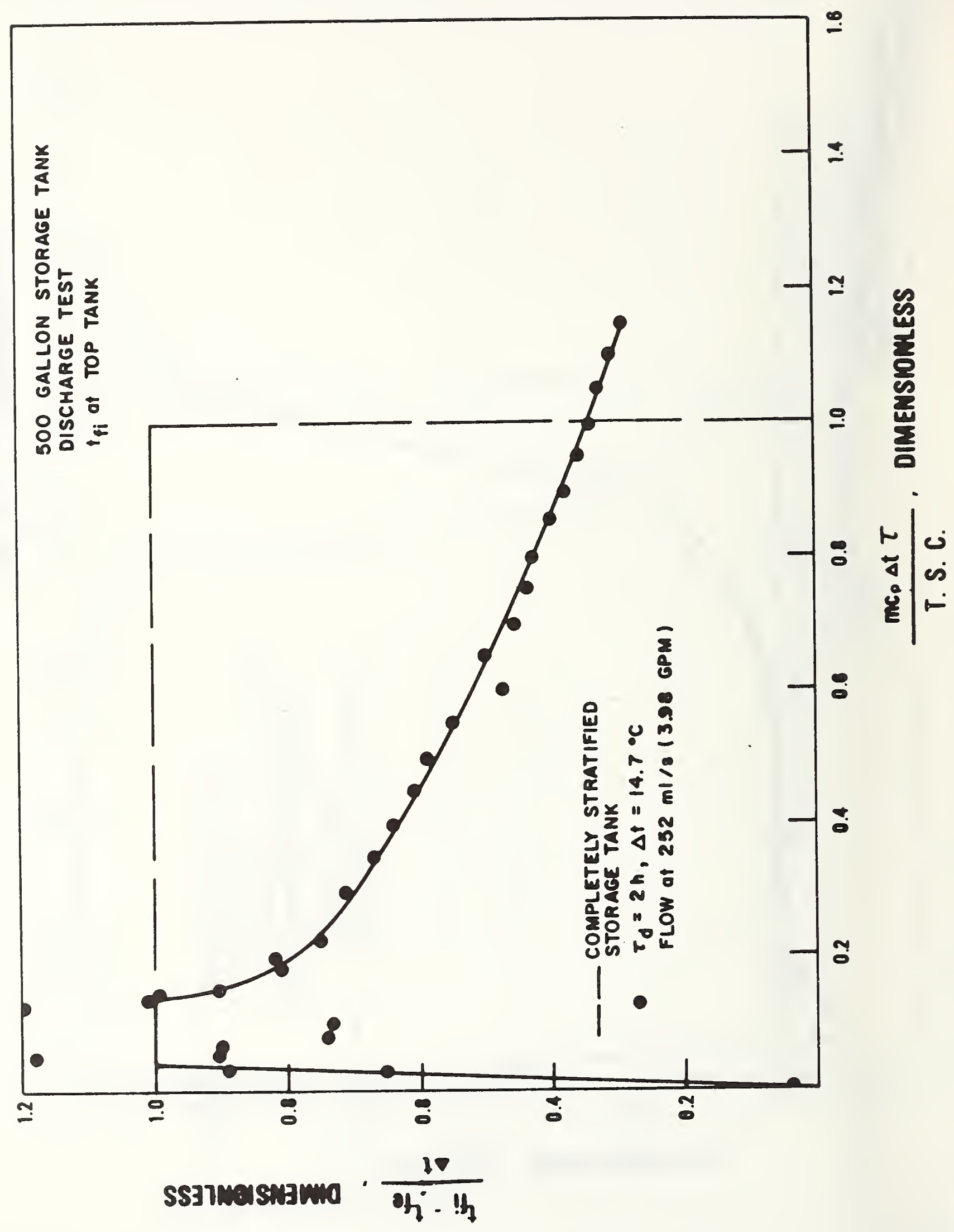




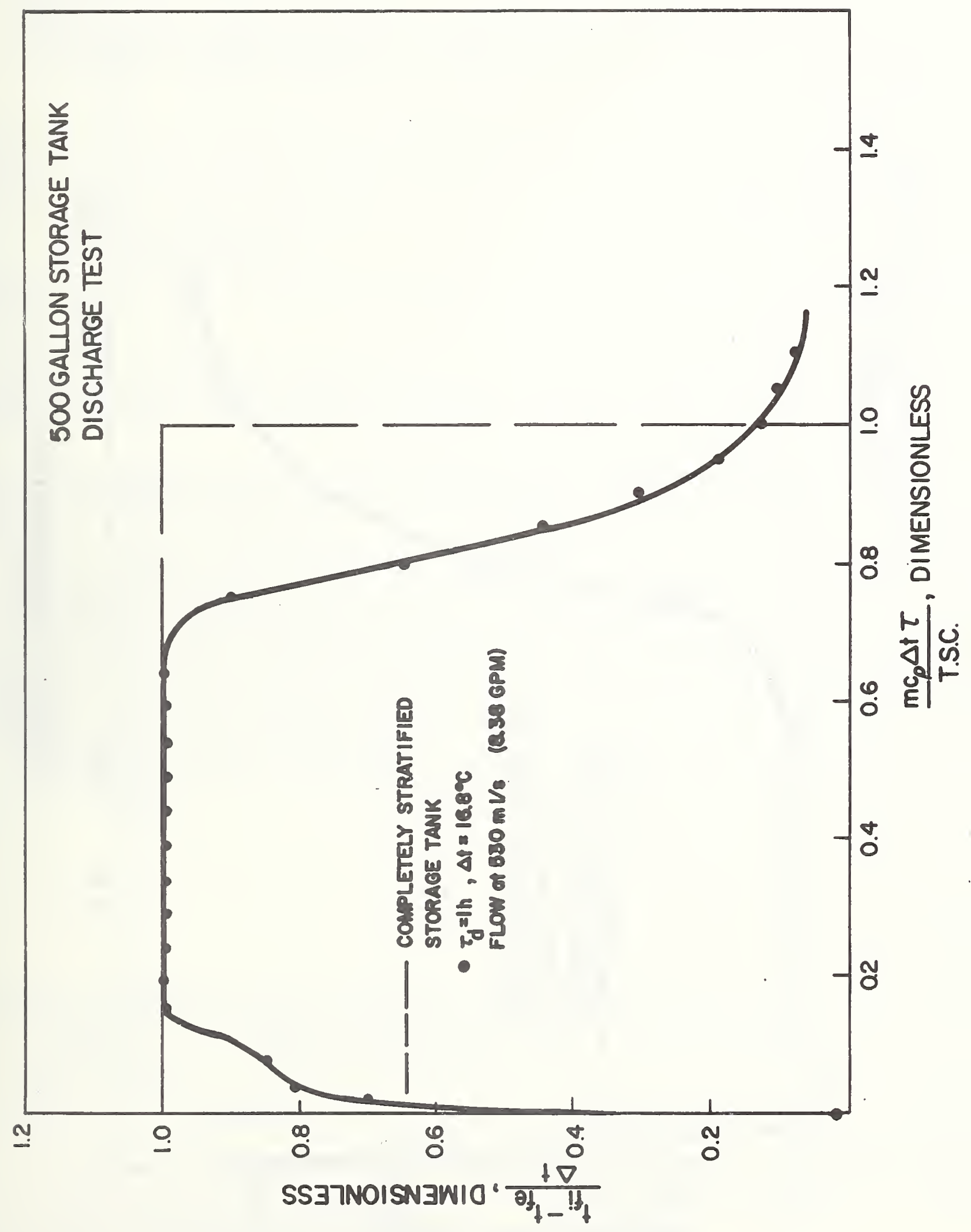




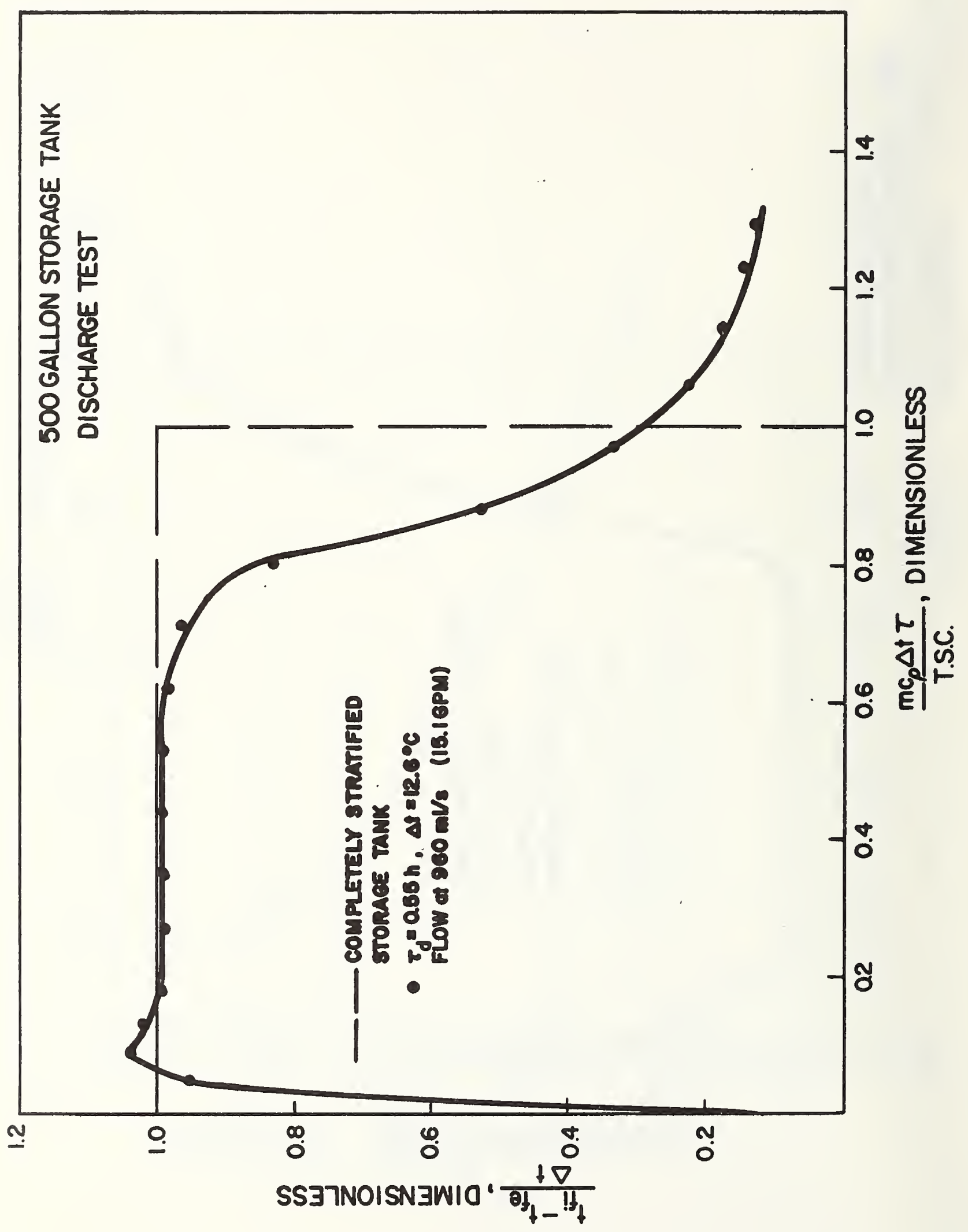



